\title{
Physical aerosol properties and their relation to air mass origin at Monte Cimone (Italy) during the first MINATROC campaign
}

\author{
R. Van Dingenen, J.-P. Putaud, S. Martins-Dos Santos, and F. Raes \\ European Commission, Joint Research Centre, Institute for Environment and Sustainability, 21020 Ispra (VA), Italy \\ Received: 13 August 2004 - Published in Atmos. Chem. Phys. Discuss.: 25 February 2005 \\ Revised: 2 June 2005 - Accepted: 1 July 2005 - Published: 19 August 2005
}

\begin{abstract}
Aerosol physical properties were measured at the Monte Cimone Observatory (Italy) from 1 June till 6 July 2000. The measurement site is located in the transition zone between the continental boundary layer and the free troposphere (FT), at the border between the Mediterranean area and Central Europe, and is exposed to a variety of air masses. Sub- $\mu \mathrm{m}$ number size distributions, aerosol hygroscopicity near $90 \% \mathrm{RH}$, refractory size distribution at $270^{\circ} \mathrm{C}$ and equivalent black carbon mass were continuously measured. Number size distributions and hygroscopic properties indicate that the site is exposed to aged continental air masses, however during daytime it is also affected by upslope winds. The mixing of this transported polluted boundary layer air masses with relatively clean FT air leads to frequent nucleation events around local noon.
\end{abstract}

Night-time size distributions, including fine and coarse fractions for each air mass episode, have been parameterized by a 3 -modal lognormal distribution. Number and volume concentrations in the sub- $\mu$ m modes are strongly affected by the air mass origin, with highest levels in NW-European air masses, versus very clean, free tropospheric air coming from the N-European sector. During a brief but distinct dust episode, the coarse mode is clearly enhanced.

The observed hygroscopic behavior of the aerosol is consistent with the chemical composition described by Putaud et al. (2004), but no closure between known chemical composition and measured hygroscopicity could be made because the hygroscopic properties of the water-soluble organic matter (WSOM) are not known. The data suggest that WSOM is slightly-to-moderately hygroscopic (hygroscopic growth factor GF at $90 \%$ relative humidity between 1.05 and 1.51), and that this property may well depend on the air mass origin and history.

Correspondence to: R. Van Dingenen

(rita.van-dingenen@jrc.it)
External mixing of aerosol particles is observed in all air masses through the occurrence of two hygroscopicity modes (average GF of 1.22 and 1.37, respectively). However, the presence of "less" hygroscopic particles has mostly such a low occurrence rate that the average growth factor distribution for each air mass sector actually appears as a single mode. This is not the case for the dust episode, where the external mixing between less hygroscopic and more hygroscopic particles is very prominent, and indicating clearly the occurrence of a dust accumulation mode, extending down to $50 \mathrm{~nm}$ particles, along with an anthropogenic pollution mode.

The presented physical measurements finally allow us to provide a partitioning of the sub- $\mu \mathrm{m}$ aerosol in four nonoverlapping fractions (soluble/volatile, non-soluble/volatile, refractory/non-black carbon, black carbon) which can be associated with separate groups of chemical compounds determined with chemical-analytical techniques (ions, non-water soluble organic matter, dust, elemental carbon). All air masses except the free-tropospheric N-European and Dust episodes show a similar composition within the uncertainty of the data $(53 \%, 37 \%, 5 \%$ and $5 \%$ respectively for the four defined fractions). Compared to these sectors, the dust episode shows a clearly enhanced refractory-non-BC fraction $(17 \%)$, attributed to dust in the accumulation mode, whereas for the very clean N-EUR sector, the total refractory fraction is $25 \%$, of which $13 \%$ non-BC and $12 \% \mathrm{BC}$.

\section{Introduction}

The importance of atmospheric aerosols in the Earth's radiative balance is well recognized through numerous field, laboratory and modelling studies that have appeared in the past decade. IPCC (2001) rates atmospheric aerosols as the least understood atmospheric component for what concerns their role in radiative forcing. In particular, the understanding of the aerosol direct forcing by carbonaceous and mineral

(C) 2005 Author(s). This work is licensed under a Creative Commons License. 
aerosol is most problematic, mostly due to a lack of knowledge of the optical properties of these compounds, and how these properties depend on the mixing state of the aerosol (Clarke et al., 2004). A thorough description of the aerosol direct effect, involves knowledge of the number size distribution, chemical size distribution, optical and hygroscopic properties of pure and mixed compounds, as well as the mixing state. The same properties are also key to understanding the indirect and semi-direct effects, related to cloud formation, scattering and absorption inside clouds, and cloud lifetime.

The Mediterranean area (Southern Europe and Northern Africa) is a growing area in terms of industry and air pollution. At the same time, it is strongly under the influence of Saharan dust emissions. The vicinity of these two sources may lead to a regional mixed plume with modified properties compared to the non-mixed plumes. It has been documented (Avila et al., 1997; Loye-Pilot et al., 1986; Casado et al., 1992) that the acidity of rain in southern Europe is considerably modified by the capacity of mineral dust to neutralize it. This in turns depends on the chemical history of the mineral dust and specifically its calcite content, which can be severely depleted after transport through polluted regions and interaction with $\mathrm{H}_{2} \mathrm{SO}_{4}$ and $\mathrm{HNO}_{3}$. It is also likely that, through such interactions, the export of pollutants from S. Europe and N. Africa and their effect on the global atmosphere will be modified (Dentener et al., 1996). In particular the atmospheric residence time of pollution and the radiative effect of pollution aerosols are expected to be modified by the degree of mixing of those aerosols with dust, complicating the estimation of the future impact on climate of increasing emissions of $\mathrm{SO}_{2}$ by developing countries (Andreae and Crutzen, 1997).

This study presents results from a one-month intensive measurement campaign, carried out at Monte Cimone (Italy, $44^{\circ} 11^{\prime} \mathrm{N}-10^{\circ} 42^{\prime} \mathrm{E}, 2165$ m.a.s.l.) as part of the MINATROC (MINeral dust And TROpospheric Chemistry) project. The measurement site is described in companion papers (e.g. Putaud et al., 2004; Balkanski et al., 2003). The Monte Cimone Station (MTC) is ideally located to monitor aged, well-mixed continental air masses with a large variety in origin and history, overlooking most of Europe, the Mediterranean and Northern Africa (Bonasoni et al., 2004).

Here we focus on aerosol physical characterisation which was performed simultaneously with gas-phase, aerosol chemical and optical measurements at the same location, results of which are presented in the present issue. This characterisation encompasses measurement of the number size distribution, hygroscopicity, volatility and equivalent black carbon content. Size-dependent hygroscopicity and volatility measurements, using differential mobility analyser (DMA) techniques, have proven in the past to provide useful information on the mixing state, processes and origin of air masses (see the overview by McMurry, 2000). The presence of non-volatile (refractory) cores in mixed sub- $\mu \mathrm{m}$ par- ticles is commonly related to combustion processes, and has proven to be a powerful tracer for the presence of anthropogenic influence. The relative contribution of volatile and refractory particle numbers in the size distribution gives information on the mixing state and on the occurrence of processes like recent nucleation or primary emission (Clarke, 1991, 1993; Clarke et al., 1997, 2004; Kreidenweis et al., 1998; Smith and O'Dowd, 1996). The volatile-to-refractory volume fraction derived from volatility measurements further yields information on the contribution of secondary aerosol compounds, added to the core by condensation or aqueous phase conversion in clouds (Baltensperger et al., 2002). Hygroscopicity measurements with a so-called Tandem-DMA (or T-DMA) can provide information on variations in water uptake among particles of a given size. T-DMA measurements have shown that when atmospheric particles of a given size are brought to high humidity, they often separate into two distinct types, which have been termed "more" and "less" hygroscopic. Numerous field studies have been using the T-DMA technique to obtain fast and reliable measurements of the aerosol mixing state and soluble fraction (Covert and Heintzenberg, 1984; McMurry and Stolzenburg, 1989; Svenningsson et al., 1992; Swietlicki et al., 1999; Baltensperger et al., 2002 and references therein; Aklilu and Muzorkewich, 2004; Kanakidou et al., 2005 and references therein). Although volatility DMA and T-DMA are no real chemical analytical techniques, they have the advantage of being fast (time resolution of minutes) and precise (very low particle sizes down to $\mathrm{nm}$ can be investigated separately).

In this study we will use the information obtained from the physical techniques mentioned above to describe the mixing state and contribution of various aerosol classes (soluble/non-soluble/refractory/BC), and relate those to chemical aerosol properties described by Putaud et al. (2004).

\section{Experimental set-up}

On-line instruments were located in a laboratory from which a main sample tube $(14 \mathrm{~cm}$ diameter) passed vertically to the outdoors platform above, from where it extended another $5 \mathrm{~m}$ vertically. The inlet was fitted with a PM10 sample head. Inside the laboratory, several secondary sample lines were connected to this central sampling tube leading to various instruments for physical and chemical aerosol characterisation. The major flow rate through the central tube was $5001 / \mathrm{min}$, of which $3501 / \mathrm{min}$ taken with a mass-flow controlled blower, and $1501 / \mathrm{min}$ by a nephelometer installed at the end of the main sample tube.

Aerosol number size distributions in the $0.006-0.6 \mu \mathrm{m}$ diameter size range, were measured with a custom-built Vienna type DMA (length $28 \mathrm{~cm}$ ), using a TSI CPC model 3010 as particle counter. The temperature difference between saturator and condenser in the CPC was enhanced to $23^{\circ} \mathrm{C}$ 
(instead of the manufacturer setting of $17^{\circ} \mathrm{C}$ ) in order to improve the detection efficiency in the $<10 \mathrm{~nm}$ size range (Mertes et al., 1995). The DMA sheath air $(7.5 \mathrm{l} / \mathrm{min})$ was re-circulated, filtered, and dried in a closed loop arrangement (Jokinen and Mäkelä, 1997) using a diaphragm pump (KNF model N 035 AN.18). The humidity of the sheath air was kept below $15 \%$. With perfectly equilibrated sheath and excess airflows, the DMA aerosol sample flow rate equals the counter flow rate $(1 \mathrm{l} / \mathrm{min})$. The flow rates of this and all other DMA systems were monitored by measuring the pressure drop over a flow restrictor and calibrated daily with a soap bubble flow meter.

Number size distributions in the diameter size range 0.3$10 \mu \mathrm{m}$ were measured in 15 size classes with an optical particle counter (OPC, GRIMM model 1.108). The optical arrangement inside the instrument is such that the scattered light is detected at an angle of $90^{\circ}$. Unlike the DMA sampling, the aerosol entering the OPC was not dried before entering the instrument. Intercomparison between DMA and OPC data in the overlapping size range $(300-600 \mathrm{~nm})$ however shows no systematic size shift in the latter. A linear regression between all hourly averaged integrated number concentration and aerosol volume for the overlapping size range of both instruments (715 data points), shows that particle counts are practically equal (slope $=1.03 \pm 0.02$ at $95 \%$ confidence level (CL), $\mathrm{R}^{2}=0.79$ ) whereas the OPC aerosol volume is slightly lower than the volume calculated from DMA (slope $=0.85 \pm 0.02$ at $95 \% \mathrm{CL}, \mathrm{R}^{2}=0.78$ ). DMA and OPC size distributions are then used to calculate integrated number and aerosol volume for the fine (particle diameter $<1 \mu \mathrm{m}$ ) and coarse (particle diameter $>1 \mu \mathrm{m}$ ) fractions.

The aerosol volatility was measured by leading the air sample (1 1/min) through a quartz tube $(20 \mathrm{~cm}$ length; $1.5 \mathrm{~cm}$ inner diameter) in a tube furnace, continuously operated at $T=300^{\circ} \mathrm{C}$, which leads to a temperature in the air stream of $270^{\circ} \mathrm{C}$, after which the resulting size distribution was measured with a second DMA (volatility DMA, V-DMA). The operating temperature was chosen in order to remove $\mathrm{H}_{2} \mathrm{SO}_{4}$, ammonium nitrate, sulfate, bisulfate, and semi-volatile organic compounds. The remaining aerosol at $T=270^{\circ} \mathrm{C}$ is commonly referred to as "refractory" aerosol and may contain non-volatile organic carbon, elemental carbon, sea salt and mineral dust (Clarke, 1991; Kreidenweis et al., 1998). The size distributions of the heated and ambient samples were measured simultaneously and with identical systems. (Note that within this context, "ambient" refers to the conditions in the standard DMA, i.e. room temperature and a humidity below 15\%). Laboratory tests with an internal mixture of sodium chloride and ammonium sulfate in a 1 to 9 volume ratio, have shown that the tube furnace arrangement is able to completely evaporate volatile compounds without renucleation or re-condensation for an aerosol volume at ambient temperature between 0.01 and $14 \mu \mathrm{m}^{3} / \mathrm{cm}^{3}$, which covers the range of aerosol loadings observed during the campaign outside dust episodes. Particle losses in the tube furnace were regularly checked by comparing the size distributions of the ambient and V-DMA with furnace switched off. This indicated that under otherwise identical conditions, the particle number at all size classes was about $20 \%$ lower in the volatility DMA than in the ambient DMA. Consequently, integrated aerosol number and volume from the volatility DMA size distributions were $78( \pm 5) \%$ and $79( \pm 6) \%$ respectively of the values obtained with the ambient DMA. Reported refractory number and volume have been corrected for this difference. The reason for the difference has not been further investigated. The fact that the losses are independent of particle size indicates that a mixing or dilution process, rather than deposition, is responsible for the lower concentration. Possibly, the sheath-to-sample air flow ratio inside the V-DMA is larger than calculated from the presumed mechanical properties of the instrument.

Although the refractory fraction could in principle contain $\mathrm{NaCl}$, chemical measurements presented by Putaud et al. (2004) confirm that sea-salt constituted less than $1 \%$ of the sub- $\mu \mathrm{m}$ aerosol mass throughout the campaign, except during the dust episode where it was $1.6 \%$ (maximum estimate, assuming that all measured $\mathrm{Na}^{+}$resulted from seasalt). This was confirmed on a few random occasions during the campaign, when the hygroscopicity of the refractory aerosol was measured with the humidity Tandem-DMA (see below). These measurements showed that on these occasions, which do not systematically cover all air mass sectors, the refractory aerosol was completely insoluble, indicating that salts were not significantly present. For the further interpretation of the data, we will presume that the refractory part does not contain sea-salt.

Aerosol hygroscopicity was measured with a tandem system of two custom-built Vienna-type DMAs, identical to the ones used for ambient and refractory size distributions. Both DMA's use a closed loop arrangement, re-circulating the sheath air over a RH conditioner and filter. The equilibration of the aerosol particles with dry or humidified air happens inside the respective DMA's, where the particles travel through the dry and humidified sheath air respectively. The sheath air of the first (dry) DMA is dried by passing the flow through an absorption drier cartridge which is replaced and regenerated when the RH approaches 15\% RH (typically once every $24 \mathrm{~h}$ ). In the second DMA, the sheath air is humidified using a Nafion humidifier (Permapure model PH-060-26-12AFS, water in shell). The DMA with humidifier was placed inside a thermally insulated box. At a constant temperature, the humidity of the air leaving the humidifier depends only on the flow rate. With a sheath air flow rate of $7.51 / \mathrm{min}$ and an ambient temperature of $26^{\circ} \mathrm{C}$, a $\mathrm{RH}$ of $87 \%( \pm 2 \%)$ was achieved. The hygroscopicity was measured sequentially for dry diameters $50 \mathrm{~nm}, 100 \mathrm{~nm}$ and $200 \mathrm{~nm}$. During each measurement, the dry diameter $\mathrm{D}_{p, d r y}$ is selected and kept constant in the first (dry) DMA while the second (humid) DMA measures the transmitted particle concentration as a function of the "wet" diameter, scanning from $0.9 \mathrm{D}_{p, d r y}$ to $2 \mathrm{D}_{p, d r y}$ 


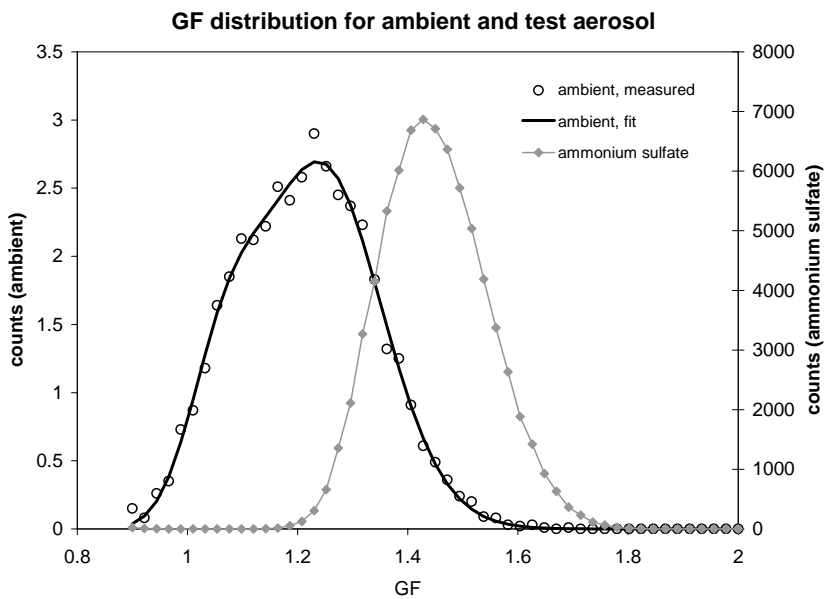

Fig. 1. Hygroscopicity measurement with T-DMA of ambient and test aerosol (ammonium sulfate), together with lognormal fit (full line). The distribution width of the test aerosol is the minimum width of a perfectly internally mixed aerosol.

in 50 classes in 5 min. The ratio $\mathrm{D}_{p, w e t} / \mathrm{D}_{p, d r y}$ is defined as the hygroscopic growth factor (GF).

Figure 1 shows a typical GF distribution for the T-DMA at $87 \% \mathrm{RH}$, for ambient aerosol and for the calibration salt ammonium sulfate. The observed spread $\sigma_{g}$ (geometric standard deviation) on the GF, is in the first place caused by the instrumental resolution, imposing a minimum width, in our case $\sigma_{g, \min }=1.07$ at $200 \mathrm{~nm}$, as derived for pure ammonium sulfate particles. Hence, completely chemically homogeneous particles (internally mixed with identical composition) would appear as a single GF peak with this minimum width. An increasing chemical heterogeneity results in a widening of the observed GF distribution, and/or the appearance of separate GF modes as has been frequently observed (McMurry and Stolzenburg, 1989; Svenningson et al., 1992; Zhang et al., 1993; Covert and Heintzenberg, 1993; Berg et al., 1998; Swietlicki et al., 2000).

The definition of a GF mode however is not always unambiguous. Figure $2 \mathrm{~b}$ shows an example of a GF distribution which can be interpreted as a single broad hygroscopicity mode with average $\mathrm{GF}=1.27, \sigma_{g}=1.10$, or as 2 partly merged modes with respective GF of 1.20 and $1.35, \mathrm{~g} \sigma_{g}=1.07$, each mode containing $50 \%$ of the particles.

In fact, irrespective of the shape of the GF distribution, one can always calculate a geometric mean GF and standard deviation of a GF spectrum with discrete bins $\mathrm{GF}_{i}$ :

$$
\begin{aligned}
& G F_{g}=\exp \left(\frac{\sum n_{i} \ln G F_{i}}{\sum n_{i}}\right), \\
& \sigma_{g}=\exp \left(\frac{\sum n_{i}\left(\ln G F_{i}-\ln G F_{g}\right)^{2}}{\sum n_{i}}\right)^{1 / 2},
\end{aligned}
$$

where $\mathrm{n}_{i}=$ particle counts in bin $\mathrm{GF}_{i}$.
On the other hand, one can fit one or more lognormal distributions to the observed GF distributions, yielding $\mathrm{GF}_{g}$ and $\sigma_{g}$ for each mode. Figure 2 shows examples of one single and three bi-modal lognormal GF distributions with modal $\sigma_{g}=1.07$ and variable separation (full line), together with a single-mode lognormal GF distribution with parameters according to Eq. (1) (dotted line). Obviously, for a single mode, Eq. (1) leads to the correct parameters to give the lognormal distribution (Fig. 2a). When more modes are present, $\sigma_{g}$ from Eq. (1) will exceed the minimum $\sigma_{g, \min }$ and the individual mode $\sigma_{g}$ 's. Hence, $\sigma_{g}$ from Eq. (1) in fact holds information on the chemical heterogeneity of the sample.

A visual analysis of bimodal model GF distributions with varying number and separation, shows that, when 2 modes with $\sigma_{g, i}=1.07$ are present, they are recognizable when the average $\sigma_{g} \geq 1.10$. Hence, for the analysis of our hygroscopicity measurements we proceeded as follows:

- Growth factor spectra for each diameter are combined into hourly averages.

- Eq. (1) is applied to calculate $\mathrm{GF}_{g}$ and $\sigma_{g}$ for hourly averages of measured GF distributions.

- Data (hourly averages) where $\sigma_{g} \geq 1.09$ are visually inspected and if 2 modes can be distinguished, a bimodal fit is applied to obtain GF and $\sigma_{g}$ for each mode.

- When only one mode is obtained, it is assigned to the "more hygroscopic" class.

All reported data are then recalculated to represent hygroscopicity at $90 \% \mathrm{RH}$, assuming ammonium sulfate as the model salt for the soluble fraction and a $\mathrm{GF}=1$ for the nonsoluble fraction (Hämeri et al., 2001). Regardless of the RH, the soluble fraction (as ammonium sulfate equivalent) for a given "monodisperse" GF can be expressed as (Virkkula et al., 1999):

$\varepsilon_{i}=\frac{G F^{3}-1}{G F_{i}^{3}-1}$

with $G F$ the measured growth factor of the mixed particle and $G F_{i}$ the growth factor of pure ammonium sulfate at the given $\mathrm{RH}$.

Hence, at $90 \% \mathrm{RH}$ :

$G F_{90}^{3}=\varepsilon_{i}\left(G F_{i, 90}^{3}-1\right)+1$

For a GF distribution, the calculated soluble fraction (Eq. 2) depends on the definition and resolution of the modes: when more modes are present, applying Eq. (2) with GF from Eq. (1) leads to an underestimation of the soluble fraction compared to a calculation applying Eq. (1) onto each resolved GF mode. Figure 3 shows how this error increases with increasing spread on the GF distribution due to the appearance and increasing separation of 2 modes with $\sigma_{g}=1.07$ 


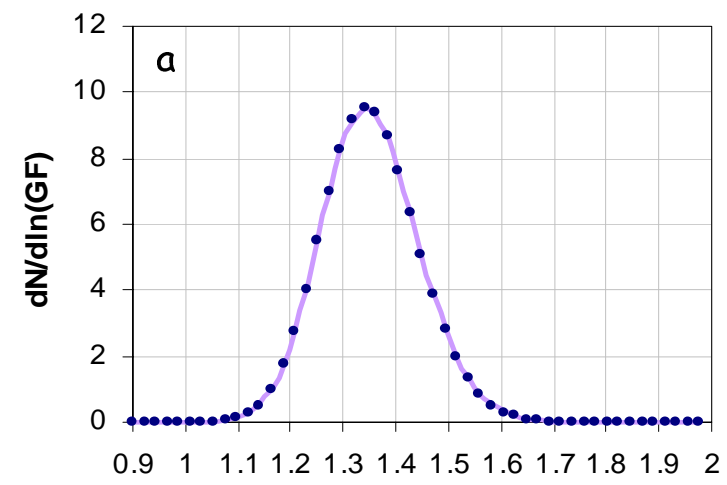

GF

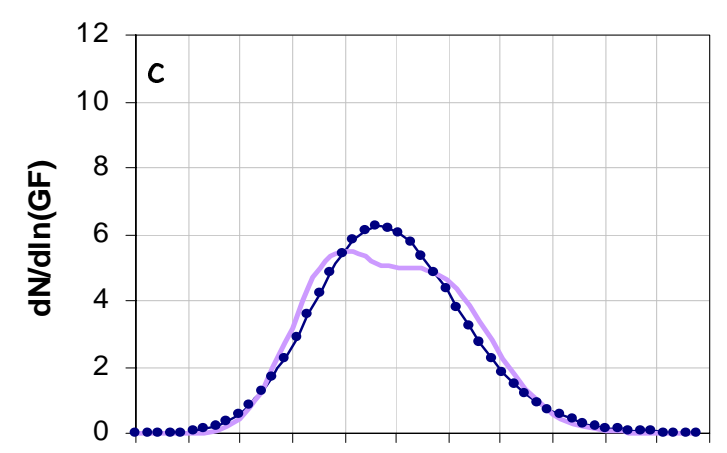

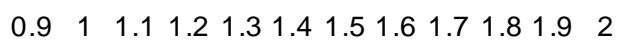

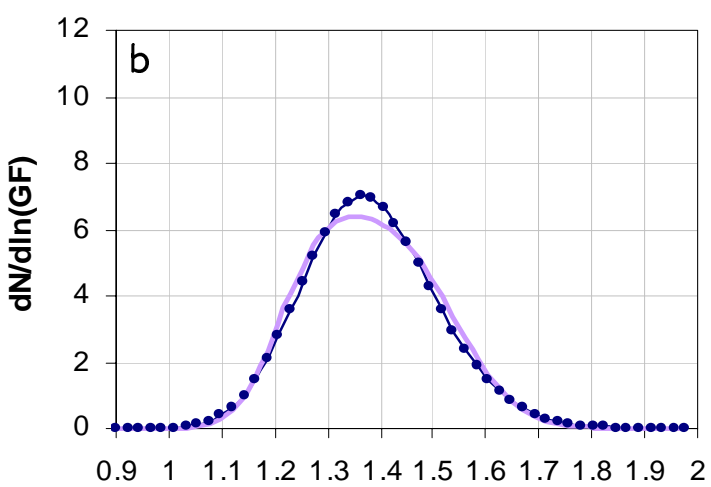

GF

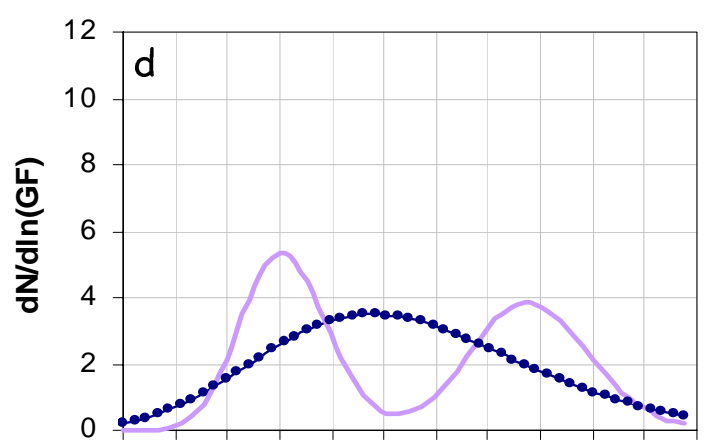

$\begin{array}{llllllllllll}0.9 & 1 & 1.1 & 1.2 & 1.3 & 1.4 & 1.5 & 1.6 & 1.7 & 1.8 & 1.9 \quad 2\end{array}$

GF

\section{GF}

Fig. 2. Analytically generated GF distributions from perfectly internally mixed (a) to gradually increasing externally mixed (b-c-d), by separating the GF into two modes with increasing distance (full line, violet). The dotted blue line represents a hypothetical single mode GF distribution based on average GF and width of the bimodal distributions (see Eq. 1 and text). Case (b) illustrates the difficulty to recognize two merged modes.

and equal number in each mode. For a 2-modal GF distribution with a dominating lower (higher) hygroscopicity mode, the error on the soluble fraction is larger (lower). However, for $\sigma_{g}<1.10$, the error (underestimation of the soluble fraction) remains in any case below $5 \%$.

Calibration of the T-DMA system with pure ammonium sulfate showed that, without humidification in DMA2, a GF of 1 was found. With humidification to $88.5 \%$, a systematic under-prediction of the GF for $200(100) \mathrm{nm}$ particles with $15 \%$ (12\%) was observed, compared to the GF for ammonium sulfate calculated from Tang and Munkelwitz (1994), combined with a correction for the Kelvin effect (Hämeri et al., 2000). Reported data are corrected for this deviation, which is attributed to the fact that the aerosol flow (1 1/min) was not RH conditioned prior to entering the DMA, as was confirmed a posteriori in laboratory tests, where a prehumidification of the sample flow resulted in a correct growth factor.

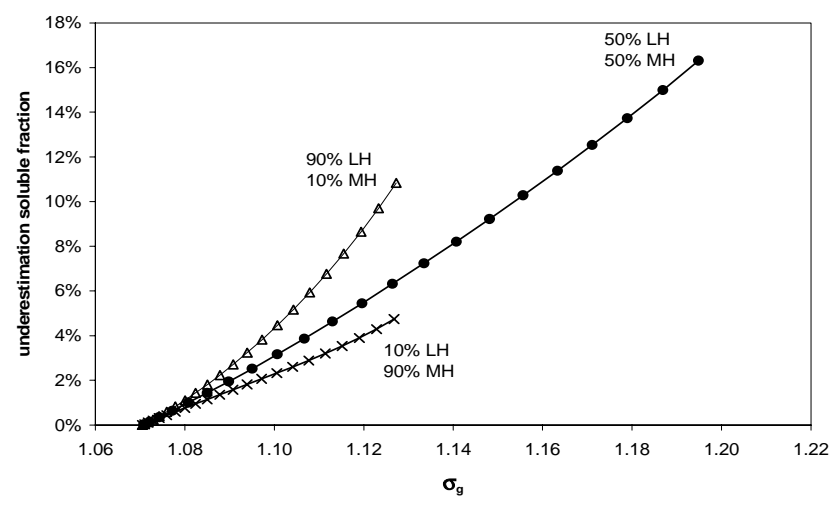

Fig. 3. Calculated error on the soluble fraction (Eq. 2) when a bimodal GF distribution (each mode with $\sigma=1.07$ ) is treated as a single lognormal mode, as function of the $\sigma_{g}$ of the overall GF distribution. 
Table 1. Averaged night-time meteorological parameters for different episodes.

\begin{tabular}{lcccc}
\hline & $\begin{array}{c}\mathrm{RH} \\
(\%)\end{array}$ & $\begin{array}{c}\mathrm{T} \\
\left({ }^{\circ} \mathrm{C}\right)\end{array}$ & $\begin{array}{c}\text { Wind speed } \\
\left(\mathrm{m} \mathrm{s}^{-1}\right)\end{array}$ & $\begin{array}{c}\% \text { of time occurring } \\
\text { (night only) }\end{array}$ \\
\hline N-EUR & 7.0 & 9.0 & 11.7 & 3 \\
NW-EUR & 82.4 & 6.7 & 5.2 & 11 \\
W-EUR & 68.3 & 7.7 & 6.7 & 22 \\
E-EUR & 55.1 & 9.1 & 4.9 & 17 \\
MED & 73.8 & 8.5 & 7.4 & 33 \\
AFR-NO DUST & 89.0 & 7.6 & 6.9 & 7 \\
AFR-DUST & 50.7 & 14.5 & 15.4 & 3 \\
\hline
\end{tabular}

The black carbon concentration was measured from the same common sample tube with a commercial GIV Aethalometer ${ }^{\mathrm{TM}}$ (incandescent lamp) with 15-min time interval and a flow rate of $5 \mathrm{l} / \mathrm{min}$. No pre-conditionning was applied to the sample air. The Aethalometer reports the "Equivalent Black Carbon" concentration (EBC) in $\mathrm{ng} / \mathrm{m}^{3}$ based on an assumed attenuation cross section of the black carbon aerosol filter deposit of $19 \mathrm{~m}^{2} \mathrm{~g}^{-1}$. Comparison between Aethalometer data and elemental carbon (EC) from impactor foils analyzed by Evolved Gas Analysis (EGA, see Putaud et al., 2004) during this campaign showed a good correlation between the datasets $\left(\mathrm{R}^{2}=0.71,44\right.$ data points), but with $\mathrm{EBC}$ giving only $45 \%$ of the impactor EC results, which indicates a specific attenuation cross section of $8.5 \mathrm{~m}^{2} \mathrm{~g}^{-1}$. Although the thermal method is still being debated, the EBC-EC correction factor lies within the range 1.9-2.5 obtained by Petzold et al. (1997). Hence, we multiplied all Aethalometer EBC concentration data with a factor $2.22(=1 / 0.45)$. An additional correction for the so-called "shadowing effect" (Weingartner et al., 2003) has not been included, because this correction becomes significant only for nearly pure black carbon particles. As shown by Putaud et al. (2004), in the present study, EC accounts for less than 7\% of the aerosol mass. Note that in the following, the term "elemental carbon" (EC) refers to the analytically determined quantity by EGA whereas "equivalent black carbon" (EBC) refers to the data obtained with the Aethalometer, with corrected attenuation factor applied. When discussing properties of the aerosol we will also use the more generic term "black carbon" (BC).

\section{Classification of air mass sectors}

Data in this study (and companion papers in this issue) have been interpreted in terms of air mass origin. Threedimensional back-trajectories arriving at MTC have been calculated using the Lagrangian FLEXTRA model (Stohl et al., 1995). For each day, the model generated eight trajectories based on the meteorological fields produced by the numerical weather prediction model of the European Center for
Medium Range Weather Forecast (ECWMF). Each trajectory was obtained for a 10 days length and a 3-h time resolution. All trajectories were visually inspected and classified according to their predominant position over one out of 6 zones over Europe before reaching the MTC observatory (see Fig. 4).

The following sectors were identified for classifying the observations:

1. Northern Europe (N-EUR); a relatively short but clearly distinct period (during $8 \mathrm{~h}$ on 18 July-19 July) corresponded to air masses directly coming from Scandinavia, transported through the free troposphere, subsiding to the measurement site from original altitude around $6000 \mathrm{~m}$. The trajectory shown in Fig. 4 belongs to this class.

2. North-West Europe (NW-EUR); a zone with expected high anthropogenic emissions, in particular nitrogen compounds;

3. Atlantic -West Europe (W-EUR); originating over the Atlantic and passing over land (France) but with less anthropogenic contribution expected than the previous case;

4. East European (E-EUR); passing over continental Europe;

5. Mediterranean area (MED);

6. African continental; originating south of $35^{\circ} \mathrm{N}$ a) Air masses not containing dust (AFR-NO DUST) b) Air masses containing dust (3-4 July), defined by in-situ measured coarse aerosol concentration and by the observation of a dust layer by the LIDAR installed $300 \mathrm{~m}$ below the station (Gobbi et al., 2003) (AFRDUST).

Table 1 shows averaged meteorological parameters for these episodes, as well the fraction of time they occurred during this field study. Note the low RH for the N-EUR episode, and the relatively high temperature during dust.

\section{Results and discussion}

Figure 5 shows a time series of the sub- $\mu \mathrm{m}$ aerosol volume $\left(V_{f}\right)$ and super- $\mu \mathrm{m}$ aerosol volume $\left(V_{c}\right.$, size range 1$10 \mu \mathrm{m})$, the integrated number concentration in the DMA size range $\left(N_{t o t}\right)$, the integrated number concentration for particles smaller than $20 \mathrm{~nm}\left(N_{20}\right)$, and EBC. Yellow and blue points indicate daytime (08:00-18:00 UTC) and night time (20:00-05:00 UTC) data, respectively. The time axis refers to local daylight saving time $(\mathrm{UTC}+2)$. The figure also indicates the type of air masses arriving at the site, according to the classification described above.

The combined data-set illustrates the occurrence of a longterm variability, linked to air mass history, modulated with a 

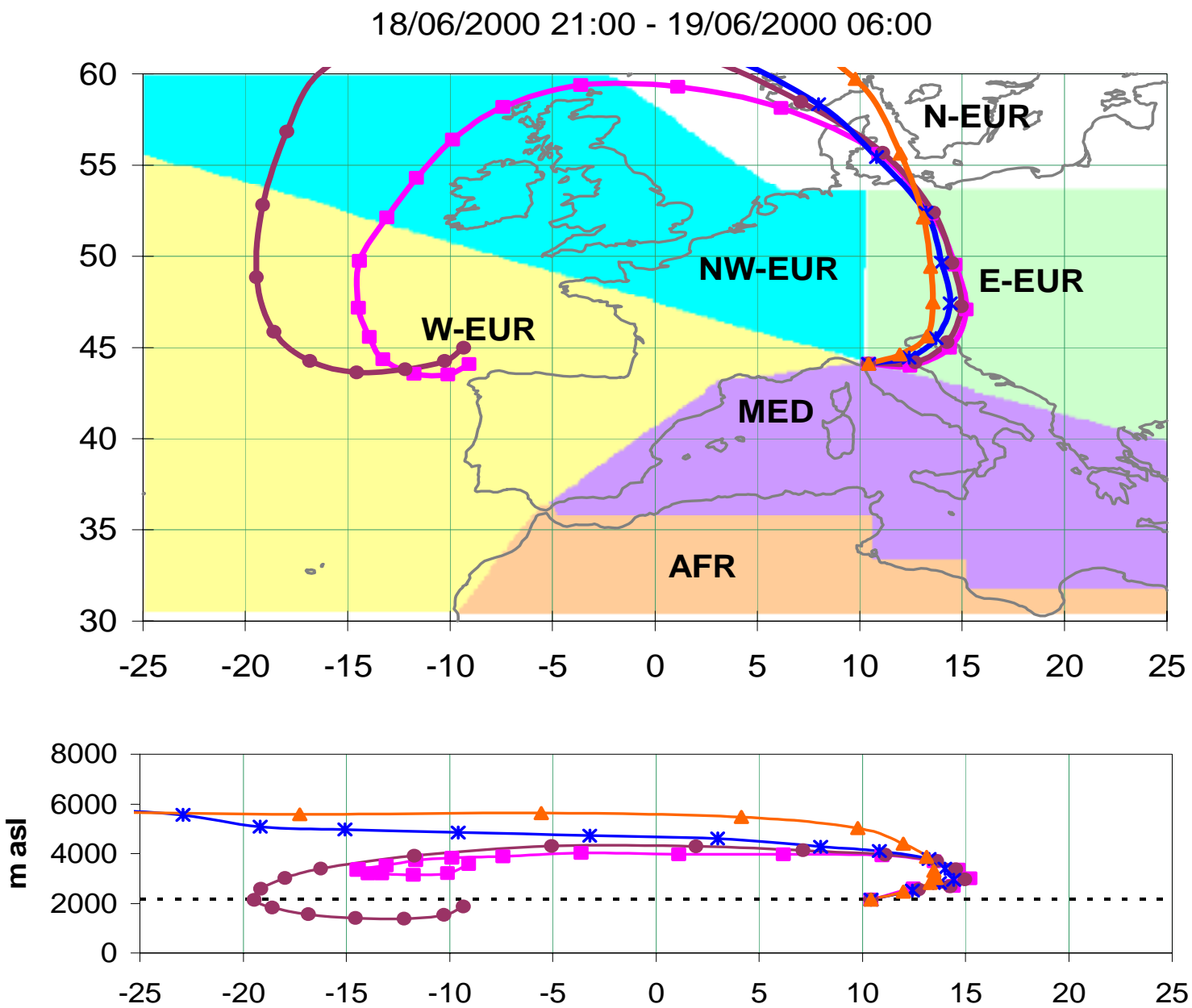

Fig. 4. Identification of the air mass zones for the classification of the trajectories. The trajectories shown on the plot correspond to the $\mathrm{N}$-EUR sector and illustrates the free tropospheric character for this sector.

diurnal variability which is particularly evident in $N_{20}$. The role of air mass origin can be inferred from variations in the night-time "baseline" of the fine aerosol volume showing higher values in the first half of the measurement period (air masses from NW Europe), and in particular in the coarse aerosol volume during the last 2 campaign days when the site was exposed to transported African dust.

\subsection{Diurnal variation and upslope winds}

Figure 6 shows average diurnal trends (with 95\% confidence level as error bars) for hourly averaged sub- $\mu \mathrm{m}$ aerosol total and ultrafine number, aerosol volume $V$, the equivalent black carbon concentration (EBC), the refractory volume and number fractions $f_{V r}$ and $f_{N r}$, the average hygroscopic growth factor at $90 \% \mathrm{RH}$ of $200 \mathrm{~nm}$ and $50 \mathrm{~nm}$ particles, and the average geometric standard deviation (width) of the GF distribution for both diameters (i.e. both GF and $\sigma_{g}$ according to Eq. 1).
Several interesting observations can be made from these average diurnal cycles. First of all, the diurnal trends, already indicated above, appear clearly in the first 3 panels, which are related to extensive (concentration dependent) properties whereas the 3 last panels, referring to aerosol intensive properties (not concentration dependent) do not show this trend. This indicates that the observed changes are rather linked to transport-related phenomena (mixing, dilution) and to a less extend to aerosol processing. During the night (22:00-07:00 local time) the lowest concentration levels are observed. Table 2 summarizes averaged values for aerosol physical parameters in night time conditions for the different sectors defined above, averaged for the time-window 00:00-07:00. It appears that properties related to the fine fraction (absorption coefficient, total number concentration, sub- $\mu \mathrm{m}$ volume) are significantly higher than the Alpine Jungfraujoch site which is part of the WMO Central European Global Atmosphere Watch (GAW) background station (Baltensperger et al., 1997) as well as for the N-Atlantic-free-troposphere 


\section{$\square$ NW-EUR $\square$ W-EUR E-EUR $\square$ MED $\square$ AFR-NO DUST $\square$ AFR-DUST $\square$ N-EUR}
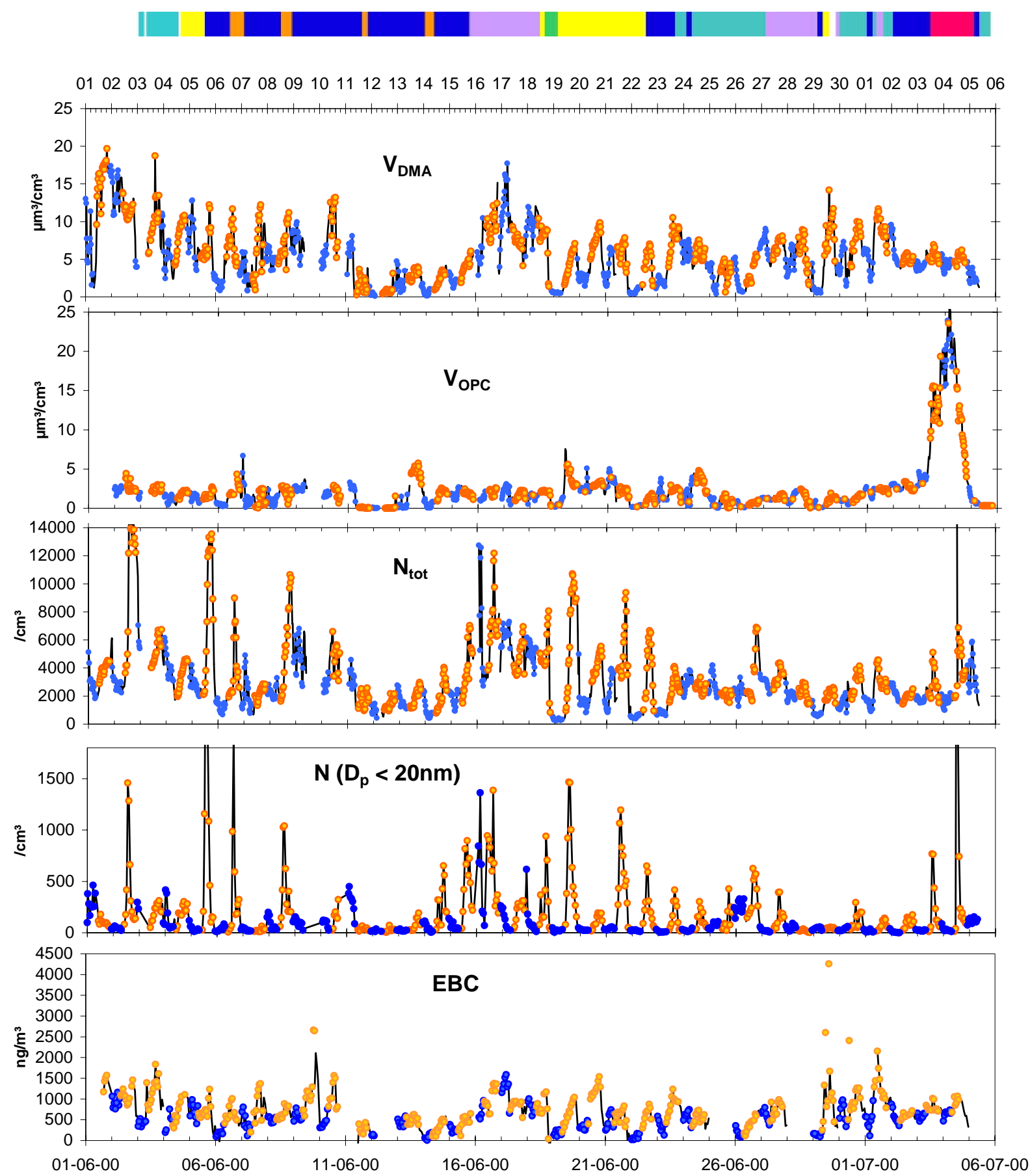

Fig. 5. Time series of various aerosol parameters during the MTC campaign. Yellow dots: day time data; blue dots: night time data. Time axis indicates local time $(\mathrm{UTC}+2)$. The colored bar on top indicates the air mass category as a function of time.

site of Izaña, Tenerife, Canary Islands (Maring et al., 2000; Van Dingenen, unpublished data). Also the relative humidity at the site remains in general relatively high during the night ( $>60 \%$ ), except during the N-EUR episode, which indicates that the site is in general not completely decoupled from the boundary layer. In conclusion, most data indicate that during the period of the campaign (June-July) the MTC site, which is at lower altitude than the "nearby" Jungfraujoch site, is actually located in a transition layer between the planetary boundary layer and the free troposphere, where in 


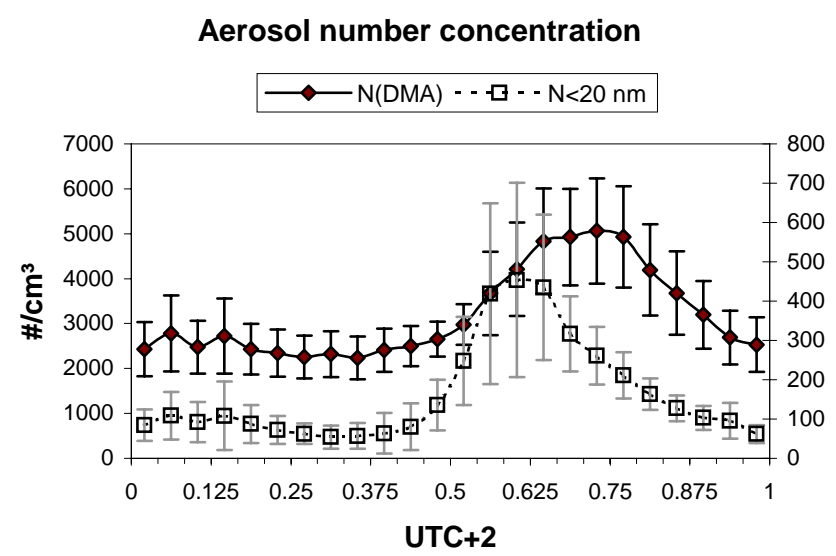

Equivalent BC

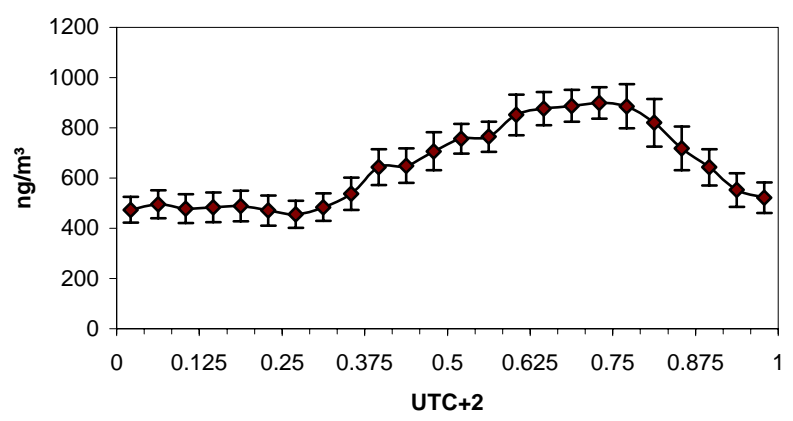

hygroscopic growth factor $(90 \% \mathrm{RH})$

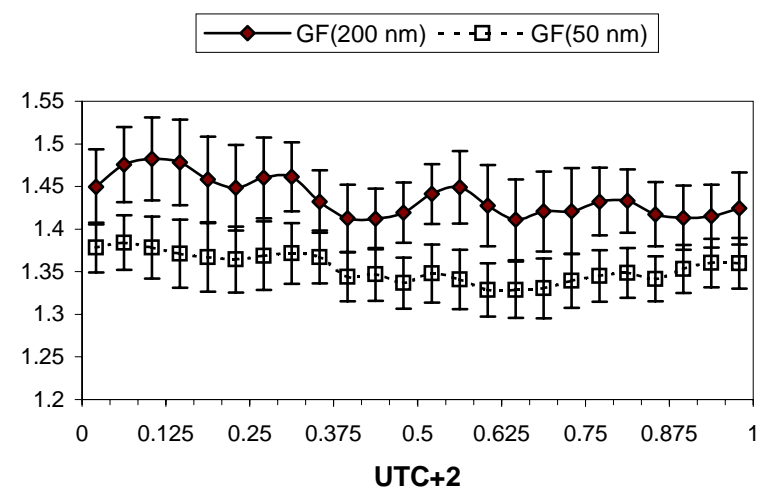

Aerosol volume

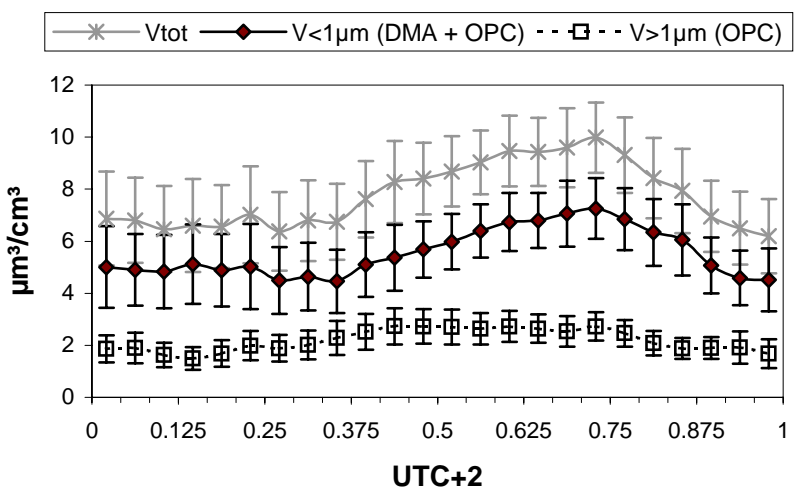

refractory fraction in number and volume

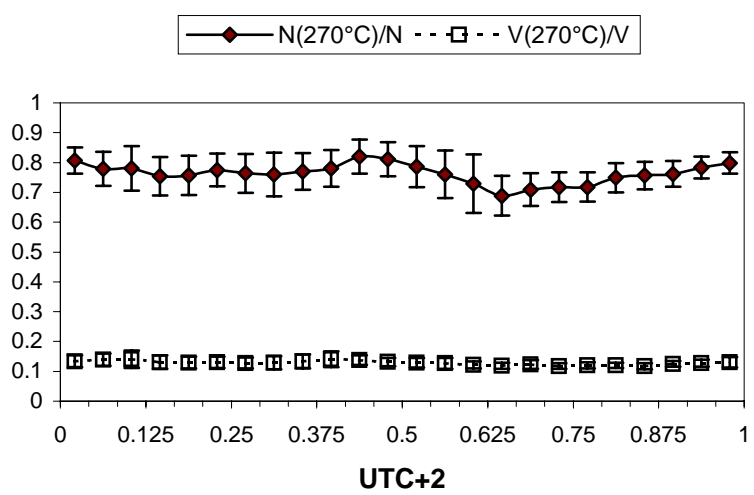

GF distribution width

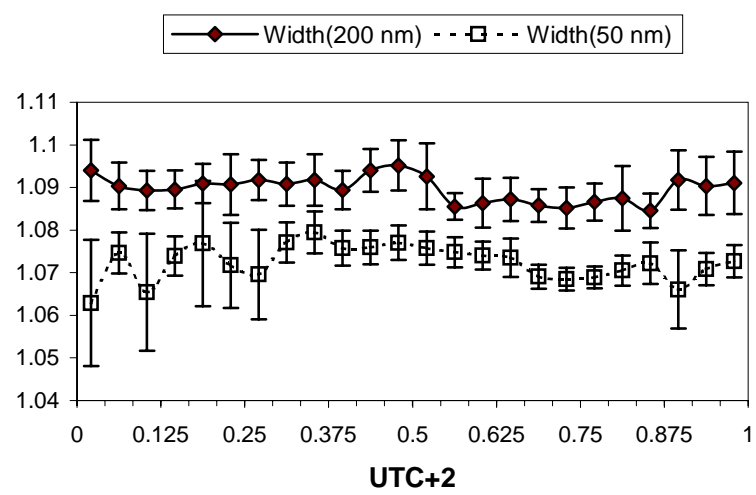

Fig. 6. Average diurnal variation (all data, mean $\pm 95 \% \mathrm{CL}$ ) of aerosol parameters at MTC.

the course of a diurnal cycle various degrees of mixing between boundary layer and free tropospheric air are observed. In fact, during the measurement campaign, only during the brief N-EUR episode, the station appeared to be exposed to pristine free-troposphere air.

Interestingly, not all aerosol properties can be explained by a linear mixing process between boundary layer and free troposphere, as is illustrated by the trend in ultra-fine par- ticles. A remarkably steep increase in the ultra-fine particles is observed to start around 11:00, more or less $2 \mathrm{~h}$ after the onset of the increase in equivalent black carbon. Figure 5 shows that this event occurs nearly daily. Whereas the increase in EBC must be related to transport (upslope winds, induced by heating of the mountain slopes) by lack of local sources, the sudden increase in ultra-fine particles gives a strong indication for new particle formation by in-situ 


\section{Correlation Coefficient of $\mathrm{dN} / \mathrm{dlog}\left(D_{p}\right)$ at all sizes with $\mathrm{BC}$}

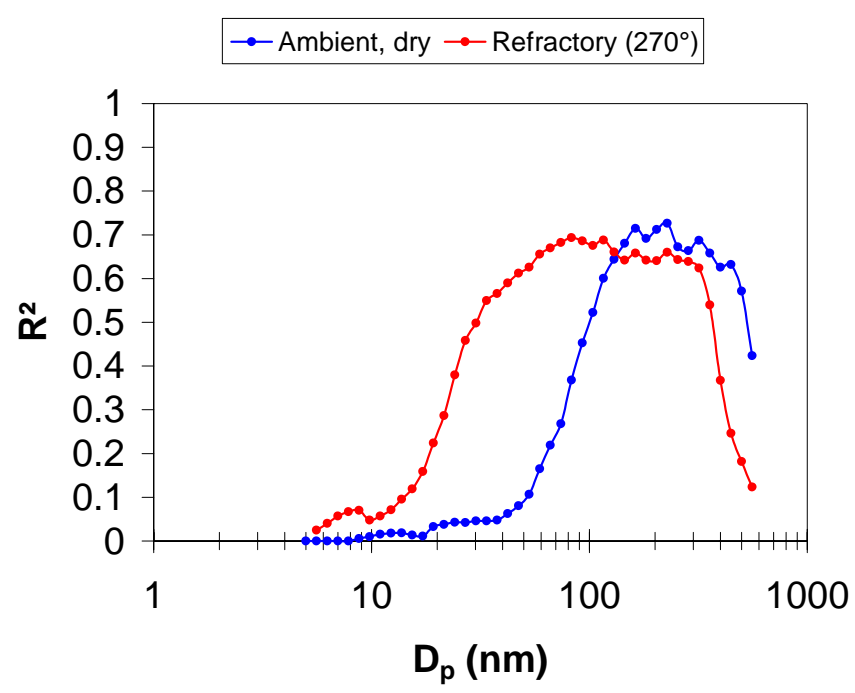

Fig. 7. Correlation coefficient between black carbon concentration and aerosol number within a narrow diameter bin for ambient temperature (red) and refractory aerosol (orange).

nucleation. Indeed, the jump in the number concentration, due to the increase in the ultra-fine size range, is not observed in the volatility DMA system, which indicates that these new particles are not formed on refractory cores, but as new, externally mixed volatile particles evaporating completely at $270^{\circ} \mathrm{C}$. One may argue that these small particles might be produced in the boundary layer, transported along with the other pollutants and become only detectable after some hours. However, nucleation events are rarely observed during the hazy summer months in the polluted North-Italian boundary layer. Rodriguez et al. (2005) performed continuous size distribution measurements in Northern Italy, and observed nucleation events on only 2 days per month during May and July of 2000 (no data available during June). In fact, nucleation in the boundary layer was only observed when exceptionally clean conditions and high solar irradiance prevailed, similar to the background conditions observed at Monte Cimone. Indeed, the formation of new particles by homogeneous nucleation critically depends on the balancing between formation in the gas-phase and scavenging by preexisting particles of condensable compounds. High concentrations of accumulation mode particles will not only scavenge the gaseous precursors of nucleation, but also reduce the lifetime of the newly formed particles, if any, by coagulation. Figure 7 shows for each particle size bin measured with the DMA, the correlation coefficient with $\mathrm{EBCg}$ or the complete campaign time series. Clearly, the hourly-averaged concentration of particles in the ultra-fine size range is not correlated with EBC $\left(\mathrm{R}^{2}<0.02\right)$, whereas particles in the ac- cumulation size range (100-300 nm) show a correlation coefficient $R^{2}>0.60$. This indicates that the diurnal variation in $N_{20}$ is not simply related to upslope transport, but rather to in-situ photochemically-induced homogeneous nucleation (where the nucleation process may well have started upwind the sampling site), whereas accumulation mode particles, like black carbon, are associated with upslope transport of more polluted boundary layer air. Hence, the transient zone between polluted boundary layer and clean free troposphere appears to provide favorable conditions for new particle formation.

\subsection{Characterisation in function of air masses}

\subsubsection{Size distribution parameters}

In what follows we will further characterize the aerosol properties in terms of the air mass sector. Table 2 gives an overview of aerosol number, volume, and EBC concentrations for the various types of air masses defined before. Only night time data have been included to exclude the influence of local pollution.

Significant differences in sub- $\mu \mathrm{m}$ aerosol volume are observed for different sectors: NW-European air masses, passing over polluted industrial and densely populated areas of the German Ruhr-area, The Netherlands and Belgium have the highest aerosol loading and black carbon level. Number concentrations and sub- $\mu \mathrm{m}$ volume are comparable for W-European, E-European, Mediterranean and nondusty African air masses. The African-dust case is characterized by a strongly enhanced super- $\mu \mathrm{m}$ aerosol volume, as expected. Very clean air was observed in N-EUR air masses (low number and sub- $\mu \mathrm{m}$ volume), however, taking into account these low levels, this episode is also characterized by a relatively high level of absorbing particles as well as super$\mu \mathrm{m}$ volume. This episode resembles most the conditions of the North-Atlantic FT observatory at Izaña, Tenerife outside dust episodes (Maring et al., 2000; Van Dingenen, unpublished data).

Averaged number $(\mathrm{N})$, surface $(\mathrm{S})$ and volume $(\mathrm{V})$ size distributions for each of the episodes are shown in Fig. 8. These data have been fitted with a 3-modal lognormal distribution, representing very well the sub- and super- $\mu \mathrm{m}$ size range. Modal parameters are given in Table 3. Note that the lognormal parameters for $\mathrm{S}$ and $\mathrm{V}$ have not been obtained independently, but have been calculated from the number size distribution fits, using the Hatch-Choate equations (Hinds, 

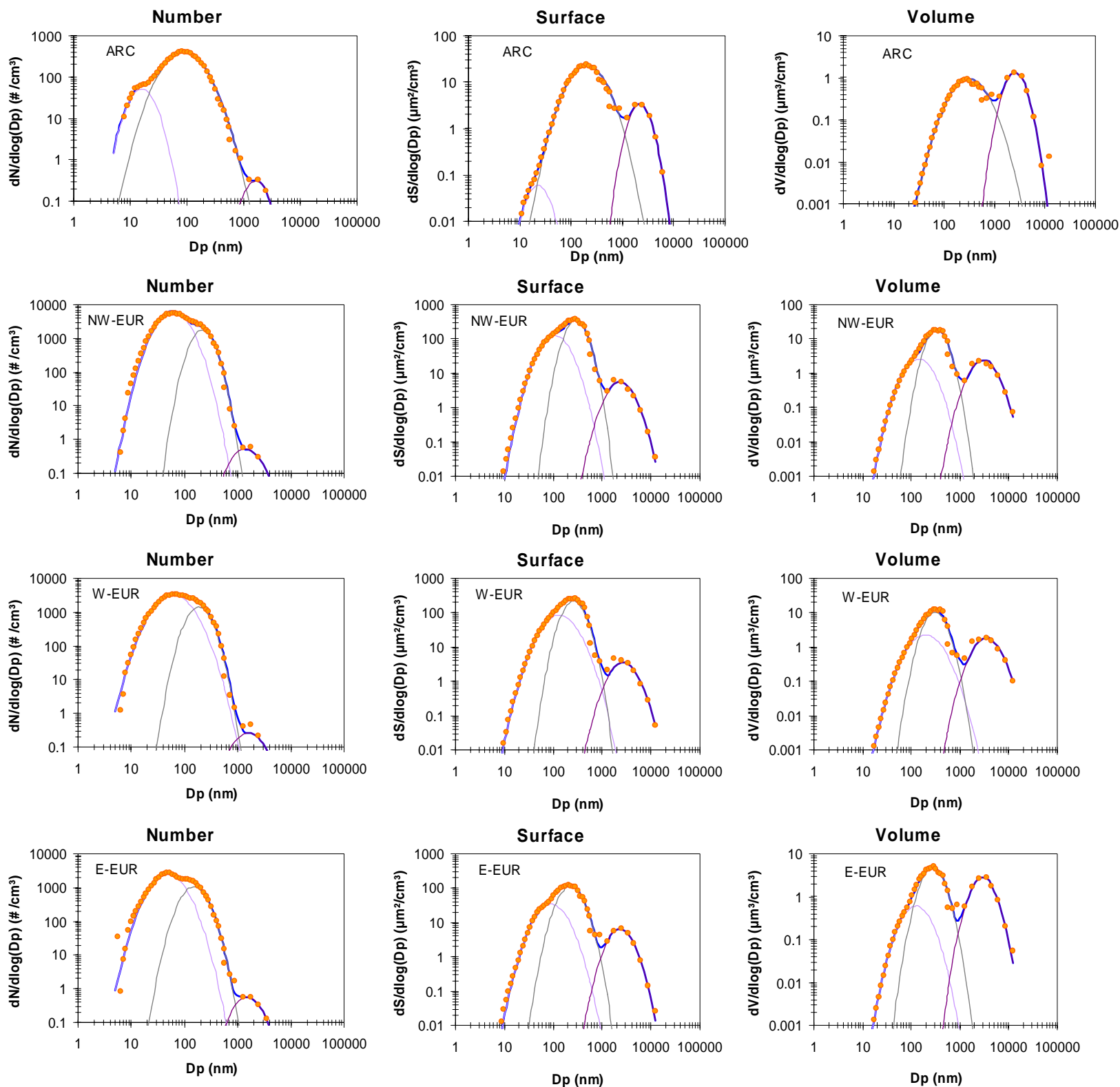

Fig. 8. Averaged number, surface and volume size distributions for the various air masses. Dots: measured averages; full lines: lognormal fits. Parameters are listed in Table 3.

1982), i.e. for modes $i=1,3$ :

$$
\begin{aligned}
& \sigma_{g N, i}=\sigma_{g S, i}=\sigma_{g V, i} \\
& D_{g S, i}=D_{g N, i} \exp \left(2 \ln ^{2} \sigma_{g N, i}\right), \\
& D_{g V, i}=D_{g N, i} \exp \left(3 \ln ^{2} \sigma_{g N, i}\right) \\
& S_{i}=\pi D_{g N, i}^{2} N_{i} \exp \left(2 \ln ^{2} \sigma_{g N, i}\right), \\
& V_{i}=\frac{\pi}{6} D_{g N, i}^{3} N_{i} \exp \left[\frac{9}{2} \ln ^{2} \sigma_{g N, i}\right]
\end{aligned}
$$

Figure 8 shows that the 9 lognormal parameters give an adequate description of the measured dry size distributions for all three moments $(\mathrm{N}, \mathrm{S}, \mathrm{V})$ over the measured size range.
The distribution properties are consistent with the air mass classifications:

All episodes show a quite similar "background" coarse mode (mode 3 ) with number mode diameter around 1.5$1.6 \mu \mathrm{m}$, and number $0.15-0.30 \mathrm{~cm}^{-3}$, except the dust episode where the average coarse mode number is $4 \mathrm{~cm}^{-3}$. In the latter case, the coarse mode contributes significantly to the sub- $\mu \mathrm{m}$ fraction for particle diameters $>500 \mathrm{~nm}$.

The accumulation mode (mode 2) shows a larger variability between the episodes, with diameter between $135 \mathrm{~nm}$ (dust) and $216 \mathrm{~nm}$ (NW-EUR), except for the N-EUR case where for mode $2, D_{g N}=88 \mathrm{~nm}$. In this case, the $2 \mathrm{nd}$ 

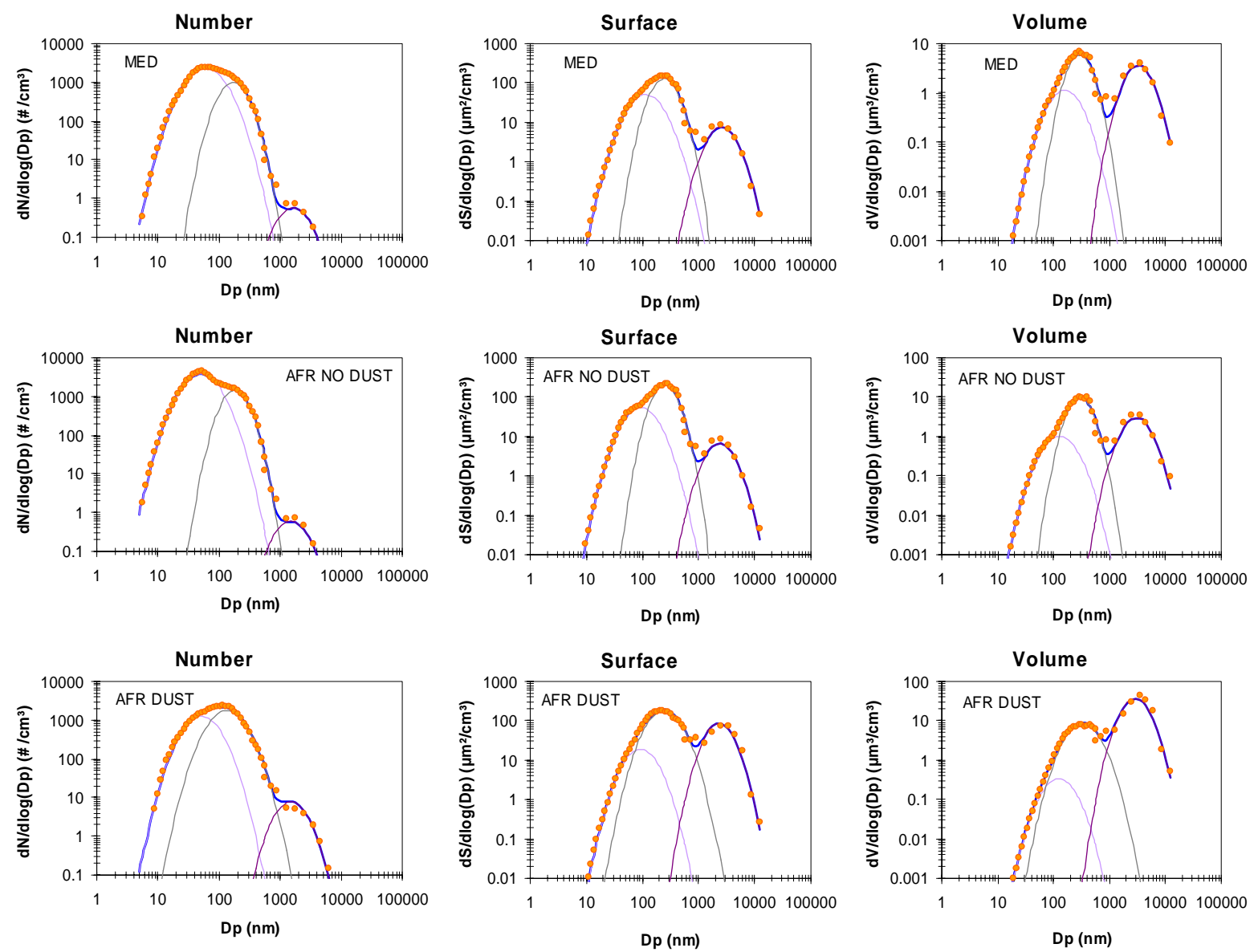

Fig. 8. Continued.

Table 2. Overview of number and volume concentrations (integrated from size distribution measurements) and equivalent black carbon.

\begin{tabular}{lcccccc}
\hline & $\begin{array}{c}\text { Number } \\
\left(\mathrm{cm}^{-3}\right)\end{array}$ & $\begin{array}{c}\text { Volume } \\
\mathrm{D}_{p}<1 \mu \mathrm{m} \\
\left(\mu \mathrm{m}^{3} \mathrm{~cm}^{-3}\right)\end{array}$ & $\begin{array}{c}\text { Volume } \\
\mathrm{D}_{p}>1 \mu \mathrm{m} \\
\left(\mu \mathrm{m}^{3} \mathrm{~cm}^{-3}\right)\end{array}$ & $\begin{array}{c}\text { Refractory Number } \\
\mathrm{D}_{p}<600 \mathrm{~nm} \\
\mathrm{~cm}^{-3}\end{array}$ & $\begin{array}{c}\text { Refractory Volume } \\
\mathrm{D}_{p}<600 \mathrm{~nm} \\
\mu \mathrm{m}^{3} \mathrm{~cm}^{-3}\end{array}$ & $\begin{array}{c}\text { EBC } \\
\left(\mathrm{ng} \mathrm{m}^{-3}\right)\end{array}$ \\
\hline N-EUR & $300 \pm 25$ & $0.59 \pm 0.03$ & $1.1 \pm 0.6$ & $258 \pm 21$ & $0.14 \pm 0.02$ & $138 \pm 194$ \\
W-Europe & $2700 \pm 230$ & $5.8 \pm 1.0$ & $1.7 \pm 0.4$ & $2029 \pm 253$ & $0.52 \pm 0.07$ & $516 \pm 35$ \\
NW-Europe & $4200 \pm 650$ & $10.3 \pm 1.4$ & $1.7 \pm 0.2$ & $3514 \pm 538$ & $0.84 \pm 0.10$ & $894 \pm 66$ \\
E-Europe & $2200 \pm 800$ & $2.9 \pm 0.6$ & $2.3 \pm 0.6$ & $1359 \pm 307$ & $0.41 \pm 0.08$ & $314 \pm 39$ \\
Mediterranean & $1900 \pm 230$ & $3.2 \pm 0.5$ & $2.4 \pm 0.9$ & $1304 \pm 148$ & $0.37 \pm 0.05$ & $422 \pm 22$ \\
African (no dust) & $3000 \pm 760$ & $5.0 \pm 1.4$ & $2.0 \pm 0.6$ & $1553 \pm 416$ & $0.36 \pm 0.07$ & $540 \pm 86$ \\
African (dust) & $1800 \pm 150$ & $5.0 \pm 0.3$ & $22.9 \pm 8.6$ & $1434 \pm 122$ & $1.15 \pm 0.19$ & $643 \pm 38$ \\
\hline
\end{tabular}

mode is actually much wider $\left(\sigma_{g}=1.91\right)$ than in the other cases, indicating that it rather consists of 2 merged modes. The highest volume is observed in the NW-EUR accumulation mode. The dust episode has a lower diameter but the highest number in the accumulation mode, indicating a less aged accumulation mode than the other cases (Van Dingenen et al., 2004).
"Aitken" modes (mode 1) have number mode diameters between 50 and $60 \mathrm{~nm}$, except again for the N-EUR case where mode 1 corresponds rather to an aged nucleation mode $\left(D_{g N}=16 \mathrm{~nm}\right)$. W and NW-EUR air masses have significantly higher volumes in the Aitken mode than the other episodes. 
Table 3. 3-modal lognormal fit parameters for averaged size distributions for the various types of air masses observed.

\begin{tabular}{|c|c|c|c|c|c|c|c|}
\hline mode & $\mathrm{N}\left(\mathrm{cm}^{-3}\right)$ & $\mathrm{D}_{g N}(\mathrm{~nm})$ & $\mathrm{S}\left(\mu \mathrm{m}^{2} \mathrm{~cm}^{-3}\right)$ & $\mathrm{D}_{g S}(\mathrm{~nm})$ & $\mathrm{V}\left(\mu \mathrm{m}^{3} \mathrm{~cm}^{-3}\right)$ & $\mathrm{D}_{g V}(\mathrm{~nm})$ & $\sigma_{g}$ \\
\hline \multicolumn{8}{|c|}{ N-EUR } \\
\hline 1 & 24 & 16 & 0.03 & 23 & 0.00 & 28 & 1.54 \\
\hline 2 & 284 & 88 & 16.00 & 204 & 0.67 & 310 & 1.91 \\
\hline 3 & 0.13 & 1622 & 1.44 & 2191 & 0.57 & 2547 & 1.47 \\
\hline \multicolumn{8}{|c|}{ NW-EUR } \\
\hline 1 & 3703 & 60 & 74 & 106 & 1.52 & 141 & 1.70 \\
\hline 2 & 752 & 216 & 148 & 291 & 7.74 & 338 & 1.47 \\
\hline 3 & 0.30 & 1411 & 3 & 2347 & 1.37 & 3026 & 1.66 \\
\hline \multicolumn{8}{|c|}{ WEST-EUR } \\
\hline 1 & 2263 & 61 & 57 & 133 & 1.55 & 197 & 1.87 \\
\hline 2 & 651 & 184 & 98 & 260 & 4.63 & 309 & 1.51 \\
\hline 3 & 0.15 & 1567 & 2 & 2693 & 1.03 & 3530 & 1.68 \\
\hline \multicolumn{8}{|c|}{ EAST-EUR } \\
\hline 1 & 1545 & 48 & 21 & 91 & 0.37 & 125 & 1.76 \\
\hline 2 & 521 & 150 & 55 & 225 & 2.30 & 277 & 1.57 \\
\hline 3 & 0.30 & 1511 & 3 & 2352 & 1.45 & 2935 & 1.60 \\
\hline \multicolumn{8}{|c|}{ MEDITERRANEAN } \\
\hline 1 & 1481 & 59 & 31 & 114 & 0.70 & 159 & 1.77 \\
\hline 2 & 468 & 169 & 61 & 245 & 2.72 & 295 & 1.54 \\
\hline 3 & 0.30 & 1622 & 4 & 2597 & 1.95 & 3286 & 1.62 \\
\hline \multicolumn{8}{|c|}{ AFRICAN - NO DUST } \\
\hline 1 & 2325 & 50 & 34 & 93 & 0.61 & 128 & 1.75 \\
\hline 2 & 638 & 182 & 92 & 252 & 4.19 & 297 & 1.50 \\
\hline 3 & 0.32 & 1496 & 4 & 2396 & 1.60 & 3032 & 1.62 \\
\hline \multicolumn{8}{|c|}{ AFRICAN - DUST } \\
\hline 1 & 745 & 51 & 11 & 93 & 0.20 & 124 & 1.72 \\
\hline 2 & 1080 & 135 & 112 & 246 & 5.33 & 332 & 1.73 \\
\hline 3 & 4.00 & 1500 & 44 & 2333 & 19.12 & 2910 & 1.60 \\
\hline
\end{tabular}

Comparing modes 1 and 2 of the present dataset with a compilation of sub- $\mu \mathrm{m}$ size distributions for European sites from background to kerbside (Putaud et al., 2003), the MTC distributions generally compare well to European natural background sites in the boundary layer.

We believe such a set of modal parameterisations is useful to establish a climatology of continental size distributions, in particular at higher altitudes where such data are scarce. In particular, remote sensing aerosol retrieval algorithms are mostly based on presumed model size distributions for a limited number of aerosol classes (Gobbi, 1995; Gobbi et al., 2003, Kahn et al., 2001). In situ-data, as the ones presented here, are needed to refine and validate these assumptions.

\subsubsection{Hygroscopicity}

Table 4 summarizes the results of the GF fitting procedure for the different air masses. The parameters for each hourly spectrum have been combined to number-weighted averages for each air mass episode and each of the 2 GF modes (when both available) which we indicate with LH (less hygroscopic) and $\mathrm{MH}$ (more hygroscopic).

$\overline{G F_{m}}=\frac{\sum G F_{g, m} n_{m}\left(G F_{g}\right)}{\sum n_{m}\left(G F_{g}\right)}, m=L H, M H$

where $n_{m}(G F)$ is the particle number in mode $m$.

A similar averaging procedure was applied to obtain the averaged number fraction of the LH mode and the averaged $\sigma_{g}$ of both modes.

\section{Results from the averaged GF spectra:}

In general, the average GF spectrum can be described by one or two modes with $\sigma_{g} \leq 1.10$. The frequency of occurrence of 2 separate modes (externally mixed aerosol) varies from a few percent (NW-EUR) to $100 \%$ of time during dust for 100 and $200 \mathrm{~nm}$ particles. Except for the dust event, the occurrence of an externally mixed aerosol is quite low; this is clearly illustrated in Fig. 9 where normalized (total number=1) and averaged night time GF spectra for each sector are presented. The number fraction of the "less hygroscopic" mode is calculated as ("fraction of time occurring" $x$ "fraction of particles in separate mode"). Except for the dust event, the overall GF spectra appear as a 
Table 4. Statistics of hygroscopic growth factors at 90\% RH (night time only) for various air mass episodes.

\begin{tabular}{|c|c|c|c|c|c|c|c|}
\hline Dp, dry (nm) & \# of hourly averages & $\begin{array}{l}\text { frequency of occurrence } \\
\text { LH mode }\end{array}$ & $\begin{array}{c}\text { fraction of } \\
\text { LH particles* }\end{array}$ & GF (LH) & GF $(\mathrm{MH})$ & $\sigma_{L H}$ & $\sigma_{M H}$ \\
\hline \multicolumn{8}{|c|}{ N-EUR } \\
\hline 50 & 7 & $14 \%$ & $51 \%$ & 1.22 & 1.37 & 1.07 & 1.09 \\
\hline 100 & 7 & $57 \%$ & $37 \%$ & 1.21 & 1.39 & 1.07 & 1.09 \\
\hline 200 & 7 & $43 \%$ & $44 \%$ & 1.21 & 1.47 & 1.09 & 1.10 \\
\hline \multicolumn{8}{|c|}{ NW-EUR } \\
\hline 50 & 22 & $5 \%$ & $7 \%$ & 0.89 & 1.27 & 1.03 & 1.07 \\
\hline 100 & 35 & $3 \%$ & $51 \%$ & 1.18 & 1.30 & 1.10 & 1.08 \\
\hline 200 & 33 & $6 \%$ & $3 \%$ & 0.94 & 1.47 & 1.06 & 1.09 \\
\hline \multicolumn{8}{|c|}{ W-EUR } \\
\hline 50 & 47 & $6 \%$ & $38 \%$ & 1.10 & 1.25 & 1.07 & 1.07 \\
\hline 100 & 70 & $10 \%$ & $27 \%$ & 1.24 & 1.32 & 1.08 & 1.08 \\
\hline 200 & 66 & $5 \%$ & $38 \%$ & 1.22 & 1.46 & 1.08 & 1.09 \\
\hline \multicolumn{8}{|c|}{ E-EUR } \\
\hline 50 & 35 & $11 \%$ & $56 \%$ & 1.29 & 1.31 & 1.06 & 1.07 \\
\hline 100 & 55 & $15 \%$ & $75 \%$ & 1.40 & 1.28 & 1.10 & 1.08 \\
\hline 200 & 53 & $19 \%$ & $35 \%$ & 1.28 & 1.41 & 1.09 & 1.08 \\
\hline \multicolumn{8}{|c|}{ MED } \\
\hline 50 & 87 & $16 \%$ & $70 \%$ & 1.27 & 1.33 & 1.07 & 1.07 \\
\hline 100 & 139 & $39 \%$ & $44 \%$ & 1.24 & 1.36 & 1.09 & 1.08 \\
\hline 200 & 132 & $39 \%$ & $34 \%$ & 1.35 & 1.50 & 1.09 & 1.08 \\
\hline \multicolumn{8}{|c|}{ AFR-NO DUST } \\
\hline 50 & 14 & $7 \%$ & $10 \%$ & 1.16 & 1.30 & 1.06 & 1.07 \\
\hline 100 & 14 & $57 \%$ & $29 \%$ & 1.27 & 1.31 & 1.11 & 1.08 \\
\hline 200 & 14 & $21 \%$ & $14 \%$ & 1.23 & 1.42 & 1.07 & 1.07 \\
\hline \multicolumn{8}{|c|}{ AFR-DUST } \\
\hline 50 & 7 & $86 \%$ & $64 \%$ & 1.29 & 1.40 & 1.08 & 1.05 \\
\hline 100 & 11 & $100 \%$ & $44 \%$ & 1.15 & 1.35 & 1.07 & 1.08 \\
\hline 200 & 12 & $100 \%$ & $64 \%$ & 1.17 & 1.46 & 1.08 & 1.08 \\
\hline
\end{tabular}

* when occurring

more or less broad single mode. The N-EUR case results as 2 modes merged into one very broad mode. Some features are discussed in more detail below.

\section{GF of dusty aerosol:}

The contribution of a less hygroscopic ( $\mathrm{LH})$ mode for the dusty air mass is very clearly increasing from 50 to $200 \mathrm{~nm}$, with even a dominant contribution in the latter case. Only in this air mass type we observe LH particles occurring $100 \%$ of the time (for 100 and $200 \mathrm{~nm}$ sizes). This is a very strong indication for the occurrence of externally mixed dust in the accumulation mode. The GF of the dust particles is consistent for 100 and $200 \mathrm{~nm}(1.15-1.17)$. During the same episode, LH $50 \mathrm{~nm}$ particles are observed $86 \%$ of time with a GF of 1.29. This frequency of occurrence is still much higher than for the other episodes, whereas the equivalent black carbon content (absolute mass as well as fraction of sub- $\mu \mathrm{m}$ volume, see Table 2) does not significantly differ from the other sectors. This indicates that small dust particles are contributing to the $50 \mathrm{~nm} \mathrm{LH}$ mode, however the higher GF indicates that they are internally mixed with soluble material. The large fraction of $\mathrm{LH}$ particles in the sub- $\mu \mathrm{m}$ size range cannot be explained by the "small end tail" of a coarse (dust) mode, as results from the number size distributions (Fig. 8). Hence, we conclude that a dust-rich, internally mixed, accumulation mode is transported along with the coarse dust mode. Chemical size distribution data (Putaud et al., 2004) indeed show the occurrence of 10 to $40 \mathrm{ng} / \mathrm{m}^{3} \mathrm{Ca}^{2+}$ in the $50-130 \mathrm{~nm}$ aerodynamic diameter size class during the dust episode, corresponding to a dust mass of 0.15 to $0.6 \mu \mathrm{g} / \mathrm{m}^{3}$. The impactor size-class resolution however is too coarse to distinguish it as a separate accumulation mode, nor does it allow to obtain information on the number concentration and the mixing state of the particles.

\section{Relation chemical heterogeneity - GF}

Figure 9 shows that in all cases and for all sizes, except for the dust episode, a wider distribution (lower maximum 
value), indicating a larger chemical heterogeneity, is associated with a higher GF. Furthermore, for a given air mass, there is a clear shift to larger GF at $200 \mathrm{~nm}$, compared to the GF distributions for 50 and $100 \mathrm{~nm}$ particles. This may indicate that a process, responsible for adding soluble material, also leads to a diversification in the chemical composition. This would be the case for cloud processing, where some of the particles of a given size may have been activated as $\mathrm{CCN}$, and others not. Condensation on the other hand would lead to a more homogeneous chemical composition of the given size fraction. This interpretation is supported by the fact that the separation between "narrow" and "broad" GF spectra is less pronounced for the $50 \mathrm{~nm}$ particles, which, for a given supersaturation, are more difficult to activate to cloud droplets than 100 and $200 \mathrm{~nm}$ particles. The spectra of the $200 \mathrm{~nm}$ particles would then indicate that air masses from Africa and Eastern Europe have experienced less cloud processing than the other ones. The N-EUR episode appears to behave differently, with the distribution broadening towards the less-hygroscopic side with increasing diameter, and practically no shift in the more hygroscopic peak. Air mass trajectories (originating in the upper free troposphere) and low $\mathrm{RH}$ indicate the absence of any cloud processing. The $200 \mathrm{~nm}$ particles appear to show the largest chemical heterogeneity of the 3 sizes, characterised by 2 broad hygroscopicity modes centred around $\mathrm{GF}=1.21$ and $\mathrm{GF}=1.47$, respectively (see also Table 4). As the presence of dust is practically excluded for this case (see the low coarse mode in Fig. 8), data suggest that hydrophobic organic and/or elemental carbon may contribute significantly to the observed particle population. This will be further discussed below.

\section{Soluble fractions}

Figure 10 shows soluble fractions (Eq. 2) obtained from the averaged hygroscopicity spectra for each episode and each size. For all cases, except dust, the $200 \mathrm{~nm}$ particles contain the highest soluble fraction of the 3 sizes. However, for the N-EUR case the increase in soluble fraction compared to the smaller sizes is much less than for the other episodes, while the N-EUR 50 and $100 \mathrm{~nm}$ particles contain the highest soluble fractions of all cases. This indicates that for the latter case, condensation, rather than cloud processing, has been the major process in adding soluble material to the particles, which is consistent with the air mass trajectories for this case, subsiding from the upper troposphere without passage in the boundary layer.

We recall that our calculation assumes that the soluble fraction behaves like ammonium sulfate, which may not be the case a priori. Putaud et al. (2004) have performed a chemical mass balance for the various episodes during this campaign, and found that in the sub- $\mu \mathrm{m}$ size range, the ionic fraction consists of ammonium nitrate and ammonium sulfate. Chan et al. (1992) have shown that the hygroscopic
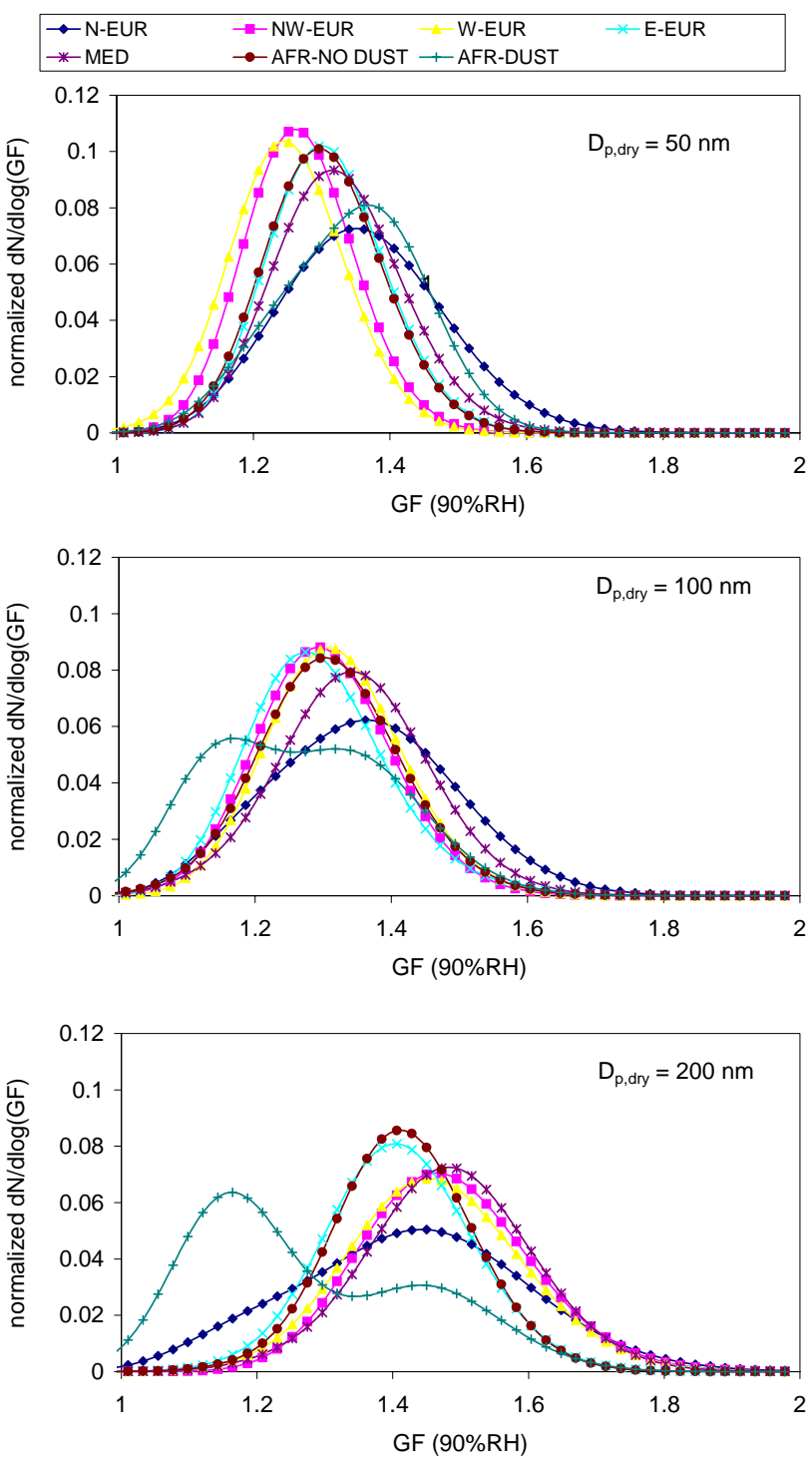

Fig. 9. Averaged normalized lognormal GF distributions for the various air masses. Parameters are given in Table 4. Upper panel: $50 \mathrm{~nm}$; middle panel: $100 \mathrm{~nm}$; lower panel: $200 \mathrm{~nm}$ particles.

behaviour of ammonium nitrate is practically equal to that of ammonium sulfate. Hence, for the ionic fraction, the assumption of ammonium sulfate as model salt is justified. Apart from major ions, Putaud et al. (2004) quantified watersoluble organic matter (WSOM), non-water-soluble organic matter (NWSOM), elemental carbon, dust and a minor remaining unidentified fraction. Of these components, WSOM (accounting for 16 to $32 \%$ of the sub- $\mu$ m mass) may contribute to the hygroscopicity of the aerosol. If WSOM is less hygroscopic than ammonium sulfate, the soluble fraction derived from the GF (with ammonium sulfate as model salt) will be underestimated and vice versa.

The diamonds in Fig. 10 show the soluble fraction calculated from the Putaud et al. (2004) dataset, assuming only 


\section{Soluble fraction in sub- $\mu \mathrm{m}$ range}

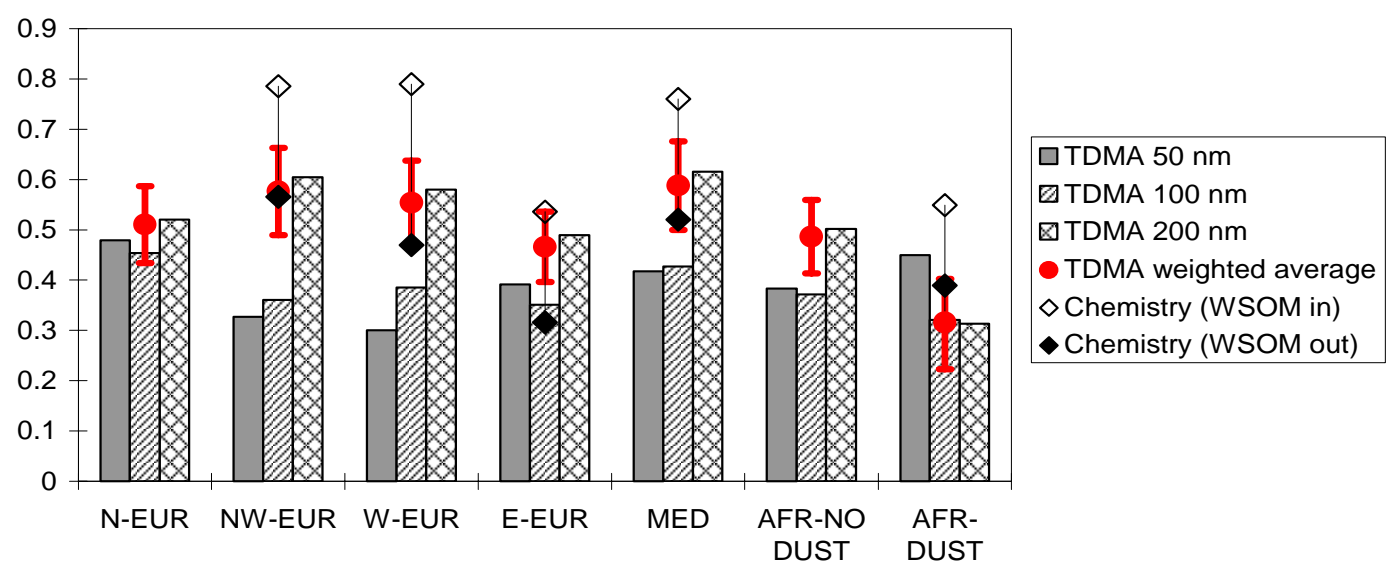

Fig. 10. Soluble fraction calculated from the GF measurements for 50, 100, and $200 \mathrm{~nm}$ particles (vertical bars), and volume-weighted average for the average size distribution (red dots). White diamonds: soluble fraction calculated from chemical composition, using ions + water soluble organic matter (see text). Black diamonds: idem, excluding water soluble organic matter.

Table 5. Weight factors of size ranges contributing to the sub- $\mu \mathrm{m}$ aerosol volume.

\begin{tabular}{lccc}
\hline & \multicolumn{3}{c}{ fraction of sub- $\mu \mathrm{m}$ volume in size range } \\
\hline & $<75 \mathrm{~nm}$ & $75-150 \mathrm{~nm}$ & $150-1000 \mathrm{~nm}$ \\
N-EUR & $2 \%$ & $14.0 \%$ & $84.1 \%$ \\
NW-EUR & $2 \%$ & $9.5 \%$ & $88.5 \%$ \\
W-EUR & $2 \%$ & $10.6 \%$ & $87.7 \%$ \\
E-EUR & $3 \%$ & $14.7 \%$ & $82.3 \%$ \\
MED & $2 \%$ & $12.3 \%$ & $85.4 \%$ \\
AFR-NO DUST & $3 \%$ & $9.5 \%$ & $87.9 \%$ \\
AFR-DUST & $1 \%$ & $9.9 \%$ & $89.0 \%$ \\
\hline
\end{tabular}

ammonium salts are responsible for the particle hygroscopicity (black symbols) or including also WSOM as a hygroscopic component with similar properties as ammonium sulphate ions (white symbols). No separate chemical data are available for the N-EUR and non-dusty African episodes. The red circles represent the distribution-averaged soluble fraction from the hygroscopicity data, by weighing the values of 50, 100 and $200 \mathrm{~nm}$ soluble fractions according to the contribution of these size fractions in the sub- $\mu \mathrm{m}$ volume (Table 5).

Figure 10 shows that the soluble fraction from the hygroscopicity data is well correlated with the chemistry data, and that, except for the dust case, the red dots lie in between the soluble fraction with and without accounting for WSOM. If the red dot coincides with the black diamond (WSOM out), it means that WSOM is not contributing to the hygroscopicity $(\mathrm{GF}=1)$. If the red dot coincides with the white diamond (WSOM in), it means that WSOM has the same hygroscopic properties as the ions $(\mathrm{GF}=1.65)$. An intermediate value implies WSOM with a lower GF than inorganic ions.

The figure shows that in four out of five cases, the hygroscopic behaviour of the sub- $\mu \mathrm{m}$ aerosol is consistent with the chemical composition if a slightly-to-moderately watersoluble organic fraction is taken into account. The "intermediate" WSOM hygroscopicity, between $\mathrm{GF}=1$ and $\mathrm{GF}=1.65$, can be formally treated as resulting from a fraction $\varepsilon_{W S O M}$ with hygroscopic GF equal to the model salt (ammonium sulfate) and a completely insoluble fraction $\left(\varepsilon_{W S O M}-1\right)$, see Eq. (2) (Hämeri et al., 2001). The corresponding GF for WSOM is then obtained from Eq. (3). For each of the sectors, we have fitted a value for $\varepsilon_{W S O M}$ such that the total soluble fraction from the chemical analysis (ions $+\varepsilon_{W} S O M \mathrm{gWSOM}$ ) matches the soluble fraction from T-DMA. The resulting $\varepsilon_{W S O M}$ and corresponding hygroscopic growth factors for WSOM are listed in Table 6. The uncertainties result from the uncertainty on the chemical composition, as given by Putaud et al. (2004). The contribution of WSOM to the soluble fraction equals $\varepsilon \times \mathrm{WSOM} /($ ions $+\varepsilon \times \mathrm{WSOM}$ ) and is listed in the last column of Table 6. The highest contribution of WSOM to the soluble fraction is found in the E-EUR sector $(32 \%)$, whereas in the others it varies between $2 \%$ and $12 \%$ (excluding the negative values for the dust case). Previous studies on the role of organics in the water uptake of atmospheric aerosols have shown a similar range: Swietlicki et al. (1999) and Malm et al. (2003) found a low to negligible contribution of organics to the aerosol hygroscopicity. On the other hand, Saxena et al. (1995) found that in non-urban locations organics account for $25-40 \%$ of the water uptake whereas in urban locations they inhibit water uptake.

Figure 10 shows that only for the dust episode, the measured T-DMA hygroscopicity is lower than expected from 
Table 6. Estimated fraction of model salt in water-soluble organic matter (WSOM), WSOM hygroscopic growth factor at $90 \%$ relative humidity, and contribution of WSOM to total sub- $\mu \mathrm{m}$ soluble fraction. Between brackets: minimum and maximum estimate from the uncertainty on chemical analysis by Putaud et al. (2004).

\begin{tabular}{lccc}
\hline & Soluble fraction $\varepsilon$ & GF $(90 \%)$ & fraction WSOM in soluble fraction \\
\hline N-EUR & - & - & - \\
NW-EUR & $0.05(-0.48,0.46)$ & $1.05(-0.90,1.38)$ & $0.018(-0.16,0.20)$ \\
W-EUR & $0.26(0.07,0.40)$ & $1.25(1.08,1.35)$ & $0.15(0.04,0.27)$ \\
E-EUR & $0.68(0.61,0.73)$ & $1.51(1.47,1.54)$ & $0.32(0.25,0.39)$ \\
MED & $0.28(0.06,0.45)$ & $1.26(1.07,1.38)$ & $0.12(0.02,0.21)$ \\
AFR-NO DUST & - & - & - \\
AFR-DUST & $-0.46(-1.14,-0.01)$ & $-0.86(-1.45,0.98)$ & $-0.23(-0.46,-0.008)$ \\
\hline
\end{tabular}

Soluble mass SJAC, impactor and T-DMA in sub- $\mu \mathrm{m}$ aerosol

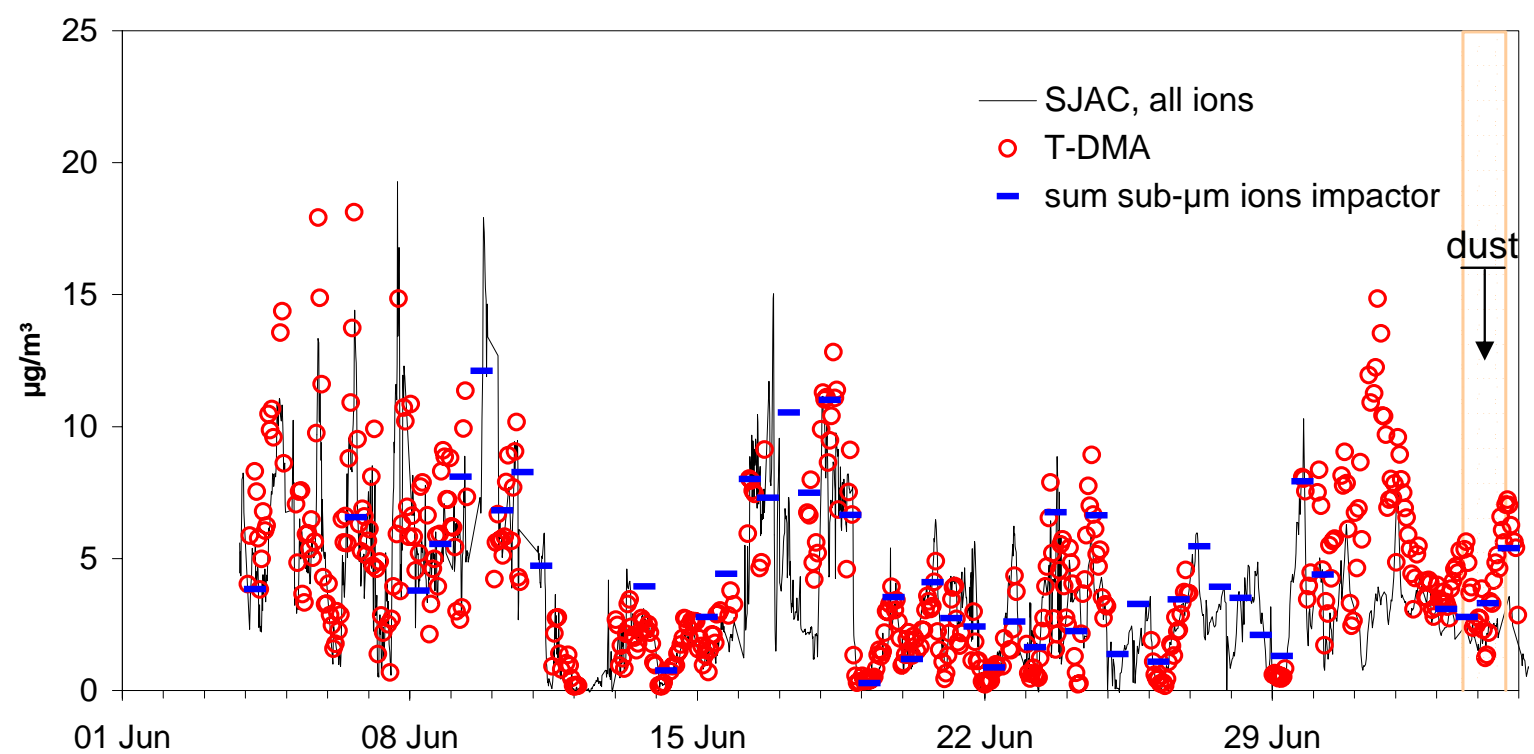

Fig. 11. Time series of soluble sub- $\mu \mathrm{m}$ mass during the MINATROC campaign, from on-line chemical analysis with the Steam Jet Aerosol Collector (SJAC), impactor sub- $\mu \mathrm{m}$ range (Putaud et al., 2004), and derived from T-DMA hygroscopicity measurements (this work).

the chemical composition, and would require a physically unlikely negative GF of -0.86 . A GF of 1 is still possible within the uncertainty however. A possible (but not demonstrated) cause for this disagreement is that the procedure used to extract soluble material from the impactor substrates, namely sonication, is more efficient to bring into solution ions associated with dust (in particular from $\mathrm{CaSO}_{4}$ ) than the gentle humidification process in the T-DMA.

Figure 11 illustrates the potential of the T-DMA as a fast and relatively easy measurement of the soluble aerosol fraction. It shows the time series of the total sub- $\mu \mathrm{m}$ soluble inorganic ion mass, obtained from the on-line chemistry measurements with the Steam Jet Aerosol Collector (SJAC), described by Putaud et al. (2004), along with the soluble mass, estimated from the T-DMA-derived soluble fraction. The latter has been multiplied with the DMA integrated aerosol volume, and with an assumed density of 1.55 (Putaud et al., 2004) for the soluble aerosol fraction to convert volume to mass. WSOM, for which no high time resolution data are available, is not included in the SJAC time series. The good agreement between the two methods, in particular in the middle part of the campaign, confirms that WSOM contributes in general relatively little to the soluble fraction, although there are two brief episodes (3 June-5 June, 30 June-2 July) where the T-DMA hygroscopicity is clearly not explained by inorganic ions only.

\subsubsection{Refractory fraction, volatility and EBC}

The night-time volatile fraction in number and volume are shown in Fig. 12a for the different air masses. The high refractory number fraction indicates that most (60-85\%) of the 


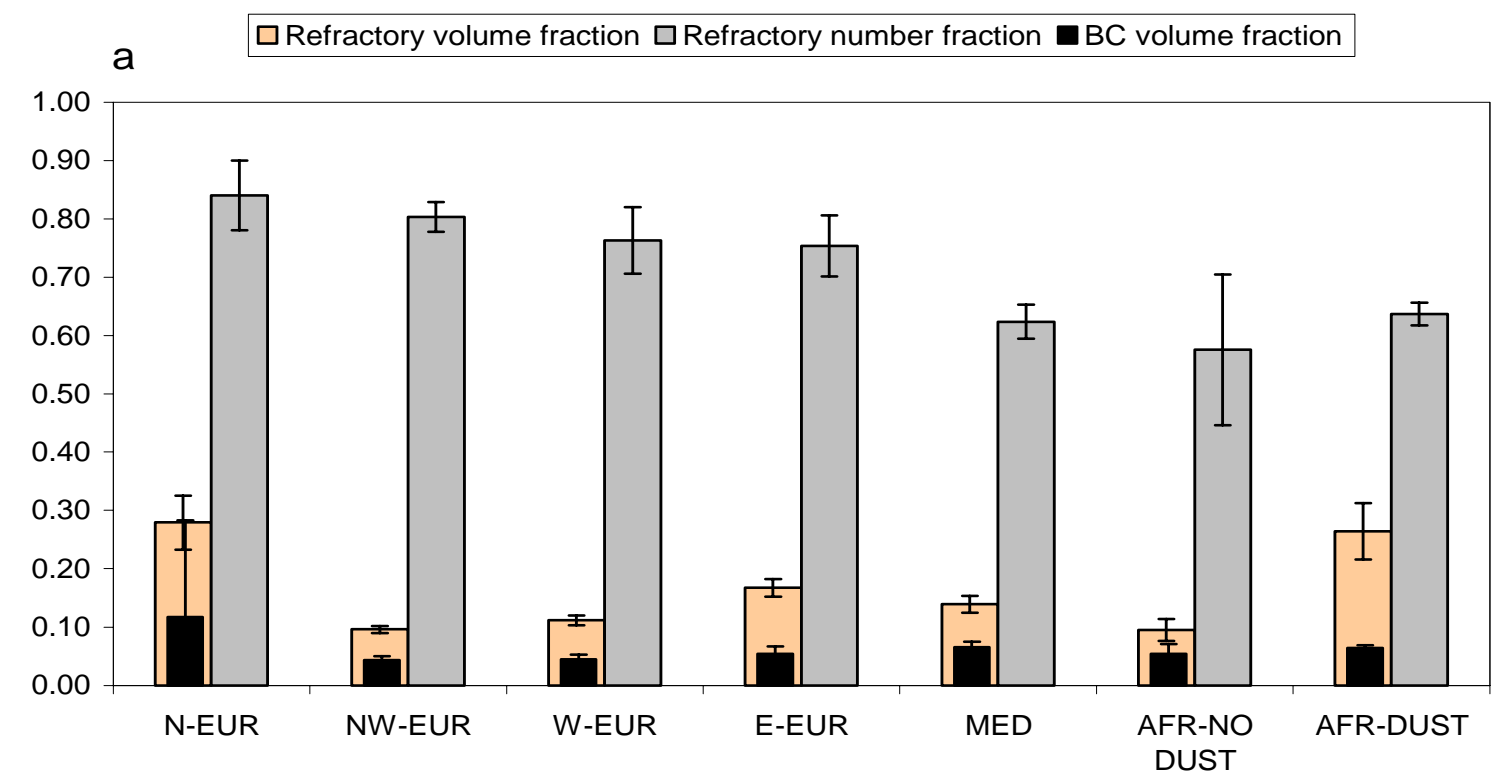

b Fraction $\mathrm{BC}$ in non-volatile volume

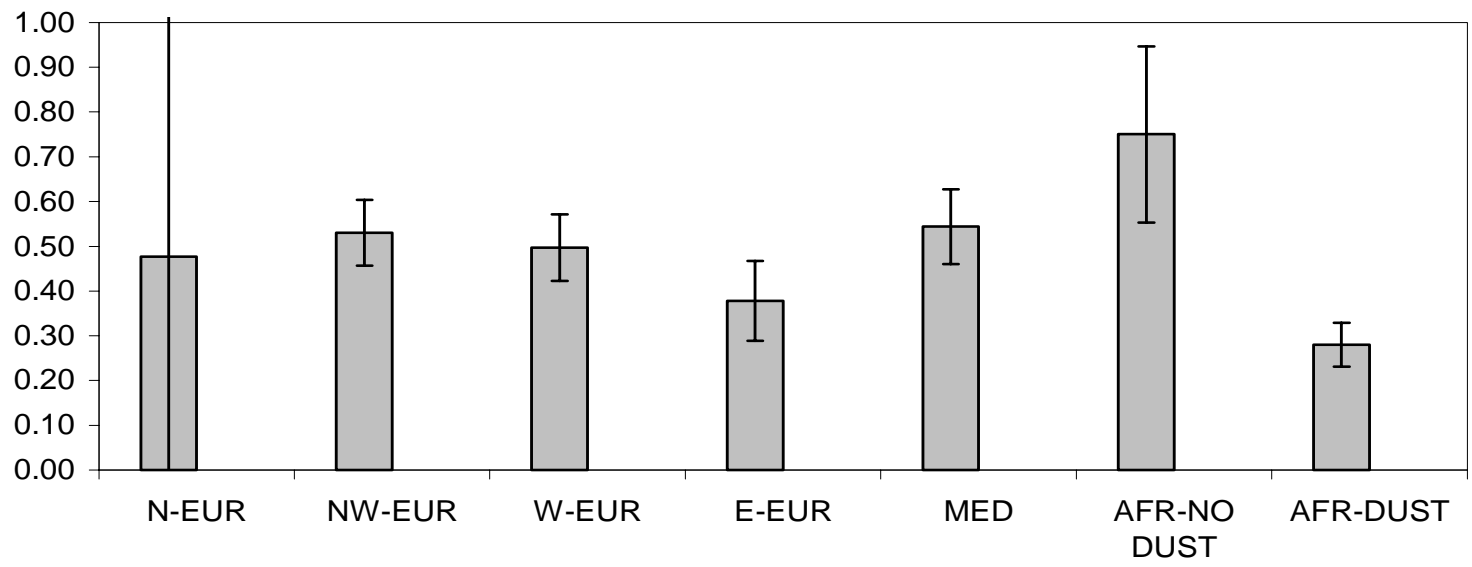

Fig. 12. Refractory number and volume fraction, and BC volume fraction for the different episodes (a); contribution of BC to the refractory fraction (b).

particles appear to contain a refractory core, whereas $7-25 \%$ of the volume is non-volatile. Figure 13 shows typical examples of ambient and refractory size distributions outside and during the dust episode. The shape of the refractory size distributions and the shift of the mode towards smaller sizes compared to the ambient distribution, indicates that most particles originally consisted of a refractory core (soot, dust, non-volatile organic carbon), mixed with semi-volatile components. The samples from Mediterranean and African sectors appear to be more externally mixed (lower fraction of refractory number) than the other cases. In Fig. 7 we already showed that the number of refractory particles with sizes between 20 and $300 \mathrm{~nm}$ is strongly correlated with the black carbon mass, indicating that black carbon is part of the refractory core of most particles. Hence, the refractory num- ber fractions can be considered as a reasonable estimate (and upper limit) for the black carbon number fraction, with the exception of the dust case where also dust particles are contributing, as inferred from the hygroscopicity and chemical data.

The highest refractory volume fractions are found for the N-EUR and African - dust cases. These are also the cases where hygroscopicity measurements already indicated a significant less-hygroscopic (LH) fraction in the sub- $\mu \mathrm{m}$ size range.

Figure 12 also shows the contribution of EBC to the sub$\mu \mathrm{m}$ volume (a) and to the refractory volume (b). The EBC volume was calculated from the measured mass (corrected for the actual attenuation cross section, see above) and an assumed density of $2 \mathrm{~g} / \mathrm{cm}^{3}$ (Fuller et al., 1999). 

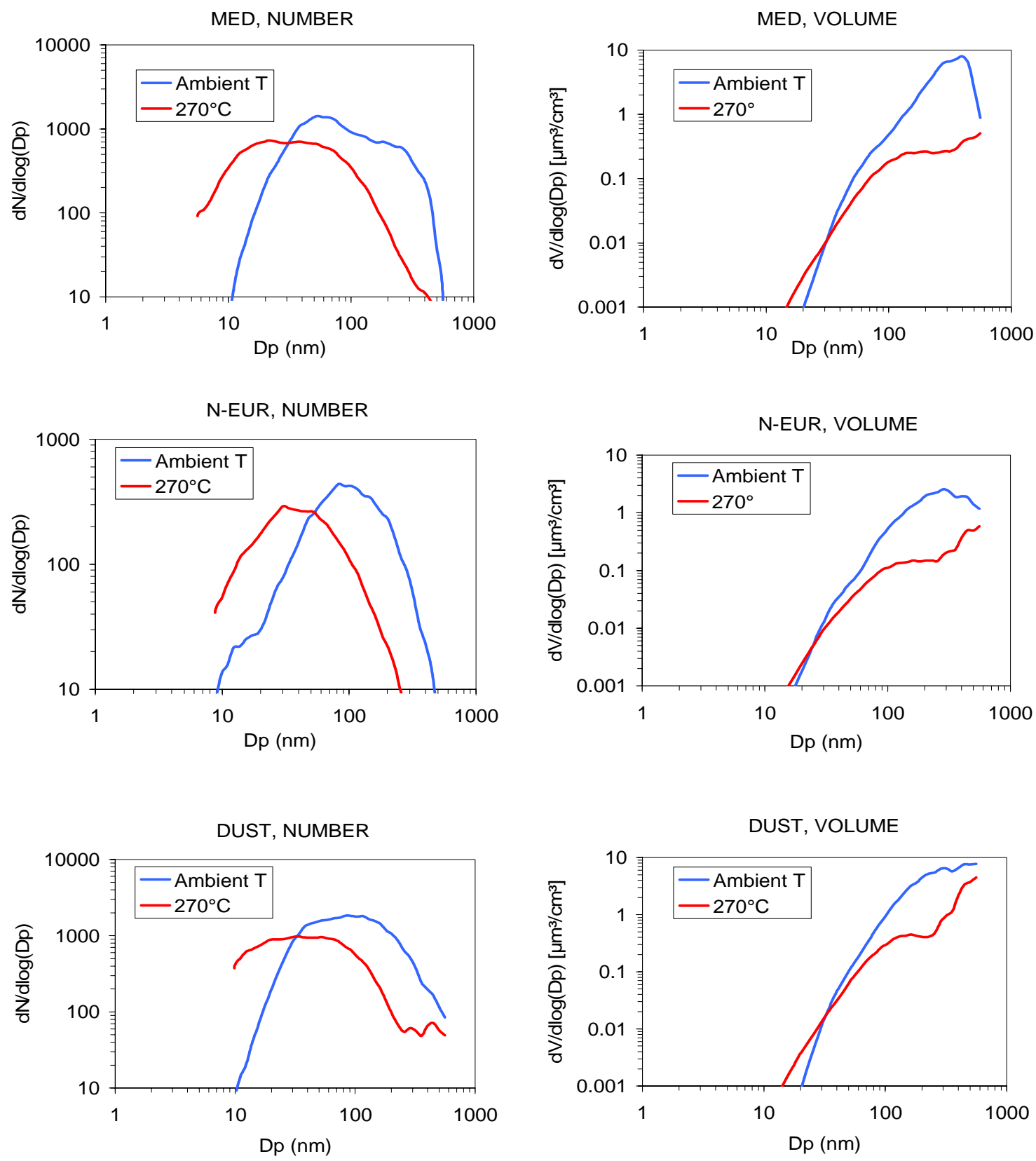

Fig. 13. Examples of ambient and refractory number size distributions.

The highest (relative) contribution of EBC to the sub- $\mu \mathrm{m}$ volume is found in the N-EUR case, however with a $100 \%$ uncertainty interval on the calculated value, due to the neardetection limit values during that episode (lowest absolute values are measured during this period). The refractory volume can be converted to an upper level estimate for black carbon of $280 \mathrm{ng} \mathrm{m}^{-3}$, consistent with the EBC value of $138 \pm 194 \mathrm{ng} \mathrm{m}^{-3}$, see Table 2. This EBC level is, for a similar mass absorption coefficient as assumed here, comparable to black carbon concentrations measured in the NorthAtlantic free troposphere from Izaña, Tenerife (11-110 ng $\mathrm{m}^{-3}$, Maring et al., 2000). Although our EBC values for the $\mathrm{N}$-EUR sector based on aethalometer measurements are quite uncertain, the presence of the refractory component is unambiguously demonstrated by the volatility measurements. The non-BC fraction of the refractory volume may further consist of aged non-volatile organic matter and some dust. Putaud et al. (2000) demonstrated that clean, free tropospheric aerosol is indeed relatively rich in organic matter, of which a significant fraction (i.e. higher than the blank value) evolves between 340 and $620^{\circ} \mathrm{C}$ in the EGA analysis. 


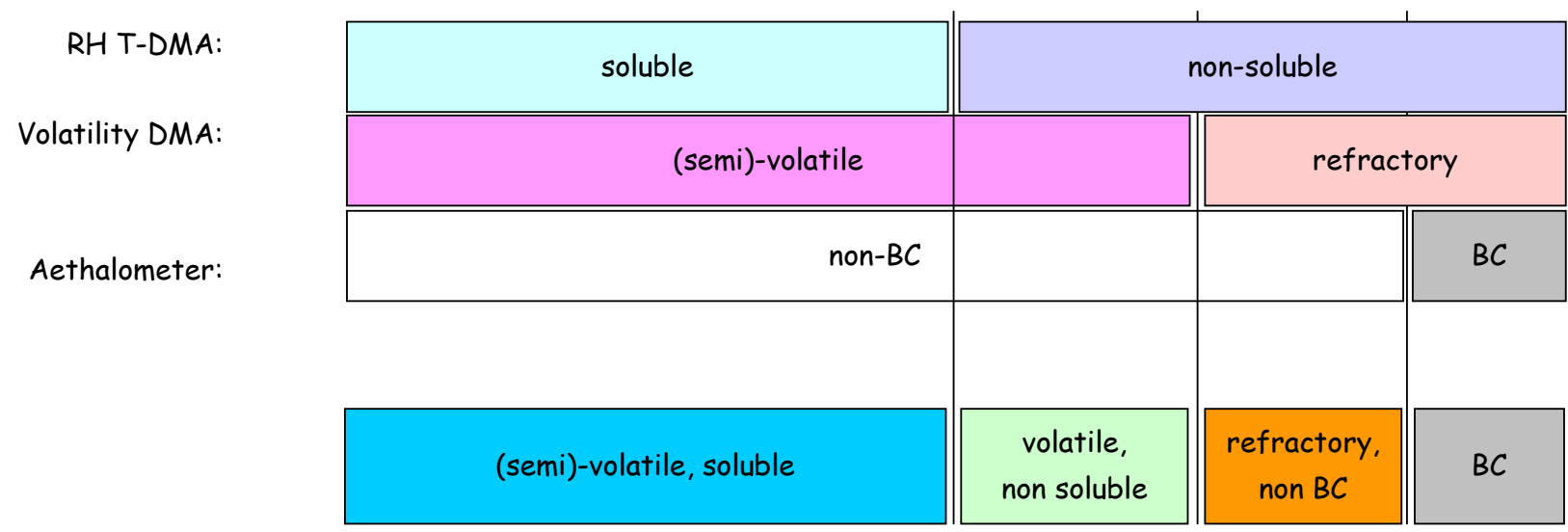

Fig. 14. Scheme for the partitioning of aerosol in four components, based on physical properties measured.

Table 7. Partitioning of the sub- $\mu \mathrm{m}$ aerosol volume in fractions based on physical measurements (upper panel) and mass fractions from the chemical mass balance (Putaud et al., 2004) (lower panel).

\begin{tabular}{|c|c|c|c|c|c|c|}
\hline & \multicolumn{2}{|c|}{ semi-volatile } & \multicolumn{2}{|c|}{ volatile } & refractory & refractory \\
\hline & \multicolumn{2}{|c|}{ soluble } & \multicolumn{2}{|c|}{ non-soluble } & non-BC & EBC \\
\hline N-EUR & \multicolumn{2}{|c|}{$0.51 \pm 0.15$} & \multicolumn{2}{|c|}{$0.24 \pm 0.15$} & \multicolumn{2}{|c|}{$0.25 \pm 0.04$} \\
\hline NW-EUR & \multicolumn{2}{|c|}{$0.58 \pm 0.16$} & \multicolumn{2}{|c|}{$0.34 \pm 0.16$} & $0.04 \pm 0.02$ & $0.04 \pm 0.01$ \\
\hline W-EUR & \multicolumn{2}{|c|}{$0.55 \pm 0.16$} & \multicolumn{2}{|c|}{$0.36 \pm 0.16$} & $0.05 \pm 0.02$ & $0.04 \pm 0.01$ \\
\hline E-EUR & \multicolumn{2}{|c|}{$0.47 \pm 0.14$} & \multicolumn{2}{|c|}{$0.39 \pm 0.15$} & $0.09 \pm 0.04$ & $0.05 \pm 0.01$ \\
\hline MED & \multicolumn{2}{|c|}{$0.59 \pm 0.16$} & \multicolumn{2}{|c|}{$0.30 \pm 0.17$} & $0.05 \pm 0.03$ & $0.06 \pm 0.01$ \\
\hline AFR-NO DUST & \multicolumn{2}{|c|}{$0.49 \pm 0.14$} & \multicolumn{2}{|c|}{$0.44 \pm 0.15$} & $0.02 \pm 0.03$ & $0.05 \pm 0.02$ \\
\hline \multirow[t]{2}{*}{ AFR - DUST } & \multicolumn{2}{|c|}{$0.32 \pm 0.11$} & \multicolumn{2}{|c|}{$0.46 \pm 0.12$} & $0.17 \pm 0.04$ & $0.06 \pm 0.01$ \\
\hline & Ions & $\varepsilon \times$ WSOM & $(1-\varepsilon) \times$ WSOM & NWSOM & dust & $\mathrm{EC}$ \\
\hline N-EUR & - & & - & & - & - \\
\hline NW-EUR & $0.65 \pm 0.09$ & $0.01 \pm 0.1$ & $0.24 \pm 0.07$ & $0.04 \pm 0.02$ & $0.008 \pm 0.004$ & $0.053 \pm 0.004$ \\
\hline W-EUR & $0.50 \pm 0.08$ & $0.09 \pm 0.06$ & $0.25 \pm 0.02$ & $0.08 \pm 0.03$ & $0.019 \pm 0.011$ & $0.066 \pm 0.007$ \\
\hline E-EUR & $0.33 \pm 0.08$ & $0.16 \pm 0.03$ & $0.07 \pm 0.10$ & $0.29 \pm 0.06$ & $0.075 \pm 0.038$ & $0.070 \pm 0.006$ \\
\hline MED & $0.56 \pm 0.08$ & $0.07 \pm 0.05$ & $0.18 \pm 0.00$ & $0.11 \pm 0.04$ & $0.022 \pm 0.012$ & $0.051 \pm 0.005$ \\
\hline AFR-NO DUST & - & & - & & - & - \\
\hline AFR - DUST & $0.39 \pm 0.20$ & $-0.08 \pm 0.05$ & $0.26 \pm 0.02$ & $0.08 \pm 0.03$ & $0.26 \pm 0.19$ & $0.048 \pm 0.006$ \\
\hline
\end{tabular}

For the dust case, it is clear that EBC accounts only for a small part $(30 \pm 5 \%)$ of the refractory volume, giving additional evidence for the presence of dust in the sub- $\mu \mathrm{m}$ range.

\subsubsection{Aerosol partitioning based on physical measurements}

In Table 7 (upper part) we summarize the partitioning of the sub- $\mu \mathrm{m}$ aerosol for all episodes in 4 fractions, based on the following assumptions:

1. The refractory aerosol is non-soluble, based on the absence of any significant amounts of sea-salt in the sub$\mu \mathrm{m}$ aerosol (Putaud et al., 2004) and occasionally measured hygroscopicity of refractory aerosol $(\mathrm{GF}=1)$.

2. black carbon occurs in the sub- $\mu \mathrm{m}$ fraction.
In that case, the following non-overlapping fractions can be derived (Fig. 14):

- soluble+semi-volatile (e.g. ammonium salts, WSOM,...)

- non-soluble+semi-volatile (NWSOM)

- refractory, non-black carbon (dust, non-volatile OM)

$-\mathrm{EBC}$

It has to be noted that also dust contributes to light absorption, albeit with a low mass absorption efficiency. Clarke et al. (2004) obtained a maximum value of $0.009 \mathrm{~m}^{2} \mathrm{~g}^{-1}$ for Asian dust. Based on the coarse and fine aerosol volume concentrations observed during the dust episode (Table 2) and 
the contribution of mineral dust in the coarse and fine fraction (73\% and 23\% respectively, see Putaud et al., 2004), dust is estimated to contribute for less than $10 \%$ to the "Equivalent BC" mass. This contribution is subtracted from the EBC fraction for the dust episode and re-assigned to the refractory EBC fraction.

The errors reported in Table 7 are calculated by error propagation theory from the random errors in all measurements (see also Putaud et al., 2004), added to the $95 \%$ confidence level on the mean. The major contribution to uncertainty in the soluble/non soluble partitioning comes from the $\mathrm{RH}$ measurement: an initial uncertainty of 3\% on RH (at 90\%) propagates to $6 \%$ uncertainty on the GF and to $17 \%$ on the soluble fraction. In the partitioning between refractory $\mathrm{BC}$ and refractory-non-BC, the detection limit and noise of the aethalometer are the major sources of uncertainty. The high uncertainty on the non-soluble-volatile fraction results from the accumulated uncertainties on the volatile and refractory fractions.

Note that the sum of all fractions equals 1 , hence the values are not independent: a lower soluble fraction implies a higher non-soluble-volatile fraction and vice versa, and similar for the partitioning between $\mathrm{BC}$ and non-BC refractory fraction.

Table 7 (lower part) also gives the mass fractions in major chemical classes obtained from the chemical mass balance in Putaud et al. (2004). We did not convert the mass fractions into volume fractions because the densities are not expected to vary much, and the fractions (unlike absolute values) would only be slightly affected. We have separated the WSOM in a fraction $\varepsilon \times \mathrm{WSOM}$, and assigned it, together with the ions under the first (soluble) column, whereas (1$\mathrm{g} \varepsilon \mathrm{p} \times \mathrm{WSOM}$ is arranged together with NWSOM under the non-soluble column.

Most cases have a volatile, soluble fraction around 50\%, except the dust case where this fraction is $32 \%$. The second most important fraction is the volatile-non-soluble one $(30-40 \%)$. Only the dust case has a significant fraction of a refractory-non-BC compound which is consistent with the specific origin of the air mass. In the N-EUR case a high refractory fraction is observed, but the high uncertainty on the $\mathrm{EBC}$ concentration in this case does not allow us to separate it in $\mathrm{BC}$ and non-BC classes.

The physical partitioning shows interesting agreements with the chemical partitioning: the semi-volatile-soluble fraction compares well to the ion fraction (apart from a minor contribution by WSOM), the volatile-non-soluble matches the OM fraction (including NWSOM and most of WSOM), as do dust and BC. We do not claim a one-to-one identification between the "physical" classes and the chemical ones, but the dataset demonstrates that the physical measurements can provide a good proxy for a fast, on-line chemical classification. In most cases the contribution of WSOM to the volatile/soluble fraction is so low that the T-DMA gives indeed an excellent record of the total inorganic mass, and the volatile/non-soluble fraction represents most of the or- ganic matter. Also the refractory/non-BC fraction is expected to contain, apart from dust, some non-volatile OM (consistent with the observation that the chemical dust fraction is lower than the refractory-non-BC fraction, except in the Dust episode), but this fraction appears to be minor compared to the volatile part.

\section{Summary and conclusions}

Aerosol physical properties were measured from 1 June till 6 July 2000 at the Monte Cimone observatory (Italy, $44^{\circ} 11^{\prime} \mathrm{N}-$ $10^{\circ} 42^{\prime} \mathrm{E}, 2165$ m.a.s.l.) as part of the MINATROC campaign. Observed diurnal variability in the aerosol properties is related to upslope wind bringing polluted air from the continental boundary layer to the site during day time (see also Fischer et al., 2003). This mixing of polluted boundary layer air into the clean free troposphere, establishes favorable conditions for new particle formation, which leads to a nearly daily observed nucleation event, with particle number concentration peaking in the early local afternoon.

In general, night-time concentrations of aerosols and EBC in particular are comparable to the European natural background, although a signature of the air mass history and upwind pollution sources can be observed.

Night-time size distributions (i.e. in absence of the daytime nucleation mode) up to $10 \mu \mathrm{m}$ for each air mass episode have been fitted with a 3-modal lognormal distribution. Number and volume concentrations in the sub- $\mu$ m modes are strongly affected by the air mass origin, with highest levels in NW-EUR air masses, versus very clean air in the N-EUR episode. During the dust episode, the coarse mode is clearly enhanced.

The observed hygroscopic behavior of the aerosol is consistent with the chemical composition described by Putaud et al. (2004), but no closure could be made because the hygroscopic properties of the water-soluble organic matter is not known. Our data suggest that WSOM is slightly-tomoderately hygroscopic, with a hygroscopic growth factor lower than ammonium salts. The derived contribution of WSOM to aerosol water uptake capacity is within the range of previous estimates in the literature (2-30\%).

Although external mixing is observed to occur in all air masses, the occurrence of "less" hygroscopic particles has mostly such a low occurrence rate ("frequency of occurrence" $x$ "fraction when occurring") that the average growth factor distribution mostly appears as a single mode. This is not the case for the dust episode, where the external mixing between less hygroscopic and more hygroscopic particles is very prominent, and indicating clearly the occurrence of an externally mixed dust accumulation mode, extending down to $50 \mathrm{~nm}$ particles. The brief but distinct $\mathrm{N}-$ EUR episode with northerly air, subsiding from the free troposphere without previous recent "contact" with the boundary layer, shows a remarkably broad GF distribution, as well 
as a high refractory fraction which is not attributable to dust and likely to consist of a mixture of organic and elemental carbon.

The presented physical measurements finally allow us to provide a partitioning of the sub- $\mu \mathrm{m}$ aerosol in four nonoverlapping fractions which can be associated with separate groups of chemical compounds: considering that the sum of the soluble fraction (based on hygroscopicity measurements) and the refractory fraction (based on volatility measurements) is less than 1 , a volatile-non-soluble fraction can be defined which can be tentatively associated with the sum of WSOM and NWSOM. Within the refractory fraction, a BC and non-BC contribution are distinguished.

For what concerns the relative contributions of the fractions, all air masses except the N-EUR and dust episodes show a similar composition within the uncertainty of the data: the soluble fraction accounts for about $53 \%$ of the sub- $\mu \mathrm{m}$ aerosol volume, the volatile/non-soluble for $37 \%$, and the dust and black carbon each for 5\%. Compared to these sectors, the dust episode shows a clearly enhanced refractory-non-BC fraction $(17 \%)$, attributed to dust in the accumulation mode, whereas for the very clean N-EUR sector, the total refractory fraction is $25 \%$, of which $13 \%$ non$\mathrm{BC}$ and $12 \% \mathrm{BC}$.

Finally, it should be noted that, although we have presented data averaged over longer time periods, each of the techniques used (size distribution, hygroscopicity, volatility and $\mathrm{EBC}$ ) has a high time resolution (some minutes) and has the advantage of yielding on-line data. DMA measurements further have a very high sensitivity compared to chemical analytical techniques. Hence, the applied method to make an aerosol partitioning based on physical measurements can be applied under conditions which are not suited for classical chemical analytical methods (high variability, low concentrations), and can therefore be a very useful tool in e.g. source apportionment studies and intensive aerosol characterization studies. By careful optimisation of the measurements, a reduction of the uncertainties is certainly possible.

Acknowledgements. We gratefully acknowledge the logistic support by the personnel of the Monte Cimone observatory and the excellent collaboration during and after the intensive campaign. This work was supported by the European Commission (DG XII) in the framework of the MINATROC project (EVK2-CT-1999-00003).

Edited by: Y. Balkanski

\section{References}

Aklilu, Y. and Mozurkewich, M.; Determination of External and Internal Mixing of Organic and Inorganic Aerosol Components from Hygroscopic Properties of Submicrometer Particles During a Field Study in the Lower Fraser Valley, Aerosol Sci. Technol., 38, 140-154, 2004.
Andreae, M. O. and Crutzen, P. J.: Atmospheric Aerosols: Biogeochemical sources and role in atmospheric chemistry, Science, 276, 1052-1058, 1997.

Avila, A., Querault-Mitjans, I., and Alarcon, M.: Mineralogical composition of African dust delivered by red rains over northeastern Spain, J. Geophys. Res., 102, 21 977-21 996, 1997.

Balkanski, Y., Bauer, S. E., Van Dingenen, R., Bonasoni, P., Schulz, M., Fischer, H., Gobbi, G. P., Hanke, M., Hauglustaine, D., Putaud, J. P., Stohl, A., and Raes, F.: The Mt Cimone, Italy, free tropospheric campaign: principal characteristics of the gaseous and aerosol composition from European pollution, Mediterranean influences and during African dust events, Atmos. Chem. Phys. Discuss., 3, 1753-1776, 2003,

SRef-ID: 1680-7375/acpd/2003-3-1753.

Baltensperger, U., Streit, N., Weingartner, E., Nyeki, S., Prévot, A. S. H., Van Dingenen, R., Virkkula, A., Putaud, J.-P., Even, A., ten Brink, H., Blatter, A., Neftel, A., and Gäggeler, H. W.: Urban and rural aerosol characterization of summer smog events during the PIPAPO field campaign in Milan, Italy, J. Geophys. Res., 107, LOP 6-1, doi:10.1029/2001JD001929, 2002.

Baltensperger, U., Gäggeler, H. W., Jost, D. T., Lugauer, M.,Schwikowski, M., Weingartner, E., and Seibert, P.: Aerosol climatology at the high-Alpine site Jungfraujoch, Switzerland, J. Geophys. Res., 102, 19707-19715, 1997.

Berg, O., Swietlicki, E., and Krejci, R.: Hygroscopic growth of aerosol particles in the marine boundary layer over the $\mathrm{Pa}$ cific and Southern Oceans during the First Aerosol Characterisation Ecperiment (ACE1), J. Geophys. Res., 103, 16 535-16545, 1998.

Bonasoni, P., Cristofanelli, P., Calzolari, F., Bonafè, U., Evangelisti, F., Stohl, A., ZauliSajani, S., Van Dingenen, R., Colombo, T., Balkanski, Y.: Aerosol-ozone correlations during dust transport episodes, Atmos. Chem. Phys., 4, 1201-1215, 2004,

SRef-ID: 1680-7324/acp/2004-4-1201.

Casado, H., Encinas, D., and Lacaux, J. P.: The moderating effect of the $\mathrm{Ca}_{2}^{+}$ion on the acidity in precipitation, Atmos. Environ., 26A, 1175, 1992.

Chan, C. K., Flagan, R. C., and Seinfeld, J. H.: Water activities of $\mathrm{NH}_{4} \mathrm{NO}_{3} /\left(\mathrm{NH}_{4}\right)_{2} \mathrm{SO}_{4}$ solutions, Atmos. Environ. 26A, 1661$1673,1992$.

Clarke, A. D.: A Thermo-optic technique for in-situ analysis of size-resolved aerosol physicochemistry, Atmos. Env., 25A, 3/4, 635-644, 1991.

Clarke, A. D.: A Global Survey of Atmospheric Nuclei in the remote Mid-Troposphere: Their Nature, Concentration and Evolution, J. Geophys. Res. Atmospheres, 98, D11, 20 633-20 647, 1993.

Clarke, A. D., Uehara T., and Porter, J.: Atmospheric nuclei and related aerosol fields over the Atlantic: Clean subsiding air and continental pollution during ASTEX, J. Geophys. Res., 102, 25 821-25 292, 1997.

Clarke, A. D., Shinozuka, Y., Kapustin, V. N., Howell, S., Huebert, B., Doherty, S., Anderson, T., Covert, D., Anderson, J., Hua, X., Moore II, K. G., McNaughton, C., Carmichael, G., and Weber, R: Size distributions and mixtures of dust and black carbon aerosol in Asian outflow: physiochemistry and optical properties. J. Geophys. Res., 109, D15S09, doi:10.1029/2003JD004378, 2004.

Covert, D. S. and Heintzenberg, J.: Measurement of the degree of internal/external mixing of hygroscopic compounds and soot in 
atmospheric aerosols, Sci. Total Environ. 36, 347-352, 1984.

Covert, D. S. and J. Heintzenberg: Size distributions and chemical properties of aerosol at Ny Alesund, Svalbard, Atmos. Environ., 27, 2989-2997, 1993.

Dentener, F. J., Carmichael, G. R., Zhang, Y., Lelieveld, J., and Crutzen, P. J.: Role of mineral aerosol as a reactive surface in the global troposphere, J. Geophys. Res., 101, 22 869-22 889, 1996.

Fischer, H., Korman, R., Klüpfel, T., Gurk, C., Königstedt, R.,Parchatka, U., Rhee, T. S., Brenninkmeijer, C. A. M., Bonasoni, P., and Stohl, A.: Ozone production and trace gas correlations during the June 2000 MINATROC intensive measurement campaign at Monte Cimone, Atmos. Chem. Phys., 3, 725-738, 2003,

SRef-ID: 1680-7324/acp/2003-3-725.

Fuller, K. A., Malm, W. C., and Kreidenweis, S. M.: Effects of mixing on extinction by carbonaceous particles, J. Geophys. Res., 104, 15 941-15 954, 1999.

Gobbi, G. P.: Lidar estimation of stratospheric aerosol properties: Surface, volume, and extinction to backscatter ratio, J. Geophys. Res., 100, 11 219-11 236, 1995.

Gobbi, G. P., Barnaba, F., Van Dingenen, R., Putaud, J. P., Mircea, M., and Facchini, M. C.: Lidar and in situ observations of continental and Saharan aerosol: closure analysis of particles optical and physical properties, Atmos. Chem. Phys., 3, 2161-2172, 2003,

SRef-ID: 1680-7324/acp/2003-3-2161.

Hämeri, K., Väkevä, M., Hansson, H.-C., Laaksonen, A.: Hygroscopic growth of ultrafine ammonium sulphate aerosol measured using an ultrafine tandem differential mobility analyzer, J. Geophys. Res., vol. 105, no. D17, 22 231-22 242, 2000.

Hämeri, K., Väkevä, M., Aalto, P. P., Kulmala, M., Swietlicki, E., Zhou, J., Seidl, W., Becker, E., O’Dowd, C. D.: Hygroscopic and $\mathrm{CCN}$ properties of aerosol particles in boreal forests, Tellus B, 53, no. 4, 359-379, 2001.

Hinds, W. C.: Aerosol Technology, Wiley and Sons, NY, 1982.

IPCC, Climate change 2001: The scientific basis. Contribution of Working Group I to the third assessment report of the Intergovernmental Panel on Climate Change, edited by: Houghton, J. T., Ding, Y., Griggs, D. J., Noguer, M., van der Linden, P. J., Dai, X., Maskell, K., and Johnson, C. A., Cambridge University Press, Cambridge, Unied Kingdom and New York, NY, USA, 881 pp., 2001

Jokinen, V. and Mäkelä, J. M.: Closed-loop arrangement with critical orifice for DMA sheath/excess flow system. Journal of Aerosol Science, vol. 28, no. 4, 643, 1997.

Kahn, R., Banerjee, P., McDonald, D.: The sensitivity of multiangle imaging to natural mixtures of aerosols over ocean, J. Geophys. Res., 106, 18 219-18 238, 2001.

Kanakidou, M., Seinfeld, J. H., Pandis, S. N., Barnes, I., Dentener, F. J., Facchini, M. C., Van Dingenen, R., Ervens, B., Nenes, A., Nielsen, C. J., Swietlicki, E., Putaud, J. P., Balkanski, Y., Fuzzi, S., Horth, J., Moortgat, G. K., Winterhalter, R., Myhre, C. E. L., Tsigaridis, K., Vignati, E., Stephanou, E. G., and Wilson, J.: Organic aerosol and global climate modelling: a review, Atmos. Chem. Phys., 5, 1053-1123, 2005,

SRef-ID: 1680-7324/acp/2005-5-1053

Kreidenweis, S. M., McInnes, L. M., and Brechtel, F. J.: Observations of aerosol volatility and elemental composition at Macquarie Island during the first Aerosol Characterization Experi- ment (ACE 1), J. Geophys. Res., 103, 16,511-16,524, 1998.

Loye-Pilot, M. D., Martin, J. M., and Morelli, J.: Influence of Saharan dust on the rain acidity and atmospheric input to the Mediterranean, Nature, 321, 427-428, 1986.

Malm, W. C., Day, D. E, Kreidenweis, S. M., Collett, J. L., and Lee, T.: Humidity-dependent optical properties of fine particles during the Big Bend Regional Aerosol and Visibility Observational Study, J. Geophys. Res., 108, 4279, ACH 13, 2003.

Maring, H., Savoie, D. L., Izaguirre, M. A., McCormick, C., Arimoto, R., Prospero, J. M., and Pilinis, C.: Aerosol physical and optical properties and their relationship to aerosol composition in the free troposphere at Izaña, Tenerife, Canary Islands, during July 1995, J. Geophys. Res., 105, 14 677-14 700, 2000.

McMurry, P. H. and Stolzenburg, M. R.: On the sensitivity of particle size to relative humidity for Los Angeles aerosols, Atmos. Environ., 23, 497-507, 1989.

McMurry, P. H.: A review of atmospheric aerosol measurements, Atmospheric Environment,34 , 1959-1999, 2000.

Mertes, S., Schröder, F., and Wiedensohler, A.: The particle detection efficiency curve of the TSI-3010 CPC as a function of the temperature difference between saturator and condenser, Aerosol Sci. Technol., 23, 257-261, 1995.

Petzold, A., Kopp, C., and Niessner, R.: The dependence of the specific attenuation cross section on black carbon mass fraction and particle size: Atmospheric Environment, 31, 661-672, 1997.

Putaud, J. P., Van Dingenen, R., Mangoni, M., Virkkula, A., Raes, F., Maring, H., Prospero, J. M., Swietlicki, E., Berg, O. H., Hillamo, R., and Mäkelä, T.: Chemical mass closure and assessment of the origin of the submicron aerosol in the marine boundary layer and the free troposphere at Tenerife during ACE2, Tellus, 52B, 141-168, 2000.

Putaud, J.-P., Van Dingenen, R., Raes, F., et al.: A European aerosol phenomenology; physical and chemical characteristics of particulate matter at kerbside, urban, rural and background sites in Europe, European Commission, Report nr. EUR 20411 EN, 2003.

Putaud, J.-P., Van Dingenen, R., Dell'Acqua, A., Raes, F., Matta, E., Decesari, S., Facchini, M. C., and Fuzzi, S.: Size-segregated aerosol mass closure and chemical composition in Monte Cimone (I) during MINATROC, Atmos. Chem. Phys., 4, 889-902, 2004,

\section{SRef-ID: 1680-7324/acp/2004-4-889.}

Rodriguez, S., Van Dingenen, R., Putaud, J. P., Martins-dos Santos, S., and Roselli, D.: Nucleation and growth of new particles in the rural atmosphere of Northern Italy - Relationship to Air Quality Monitoring, Atmos. Environ., in press, 2005.

Saxena, P., Hildeman, L. M., McMurry, P. H., and Seinfeld, J. H.: Organics alter hygroscopic behavior of atmospheric particles, J. Geophys. Res., 100, 18 755-18770, 1995.

Smith, M. H. and O'Dowd, C. D.: Observations of accumulation mode aerosol composition and soot carbon concentrations by means of a high-temperature volatility technique, J. Geophys. Res., 14: 19583-19591, 1996.

Stohl, A., Wotawa, G., Seibert, P., and Kromp-Kolb, H.: Interpolation errors in wind fields as a function of spatial and temporal resolution and their impact on different types of kinematic trajectories, J. Appl. Meteorol., 34, 2149-2165, 1995.

Svenningson, I. B., Hansson, H. C., Widensohler, A., Ogren, J. A., Noone, K. J., and Hallberg, A.: Hygroscopic growth of aerosol particles in the Po Valley, Tellus, 44B, 556-569, 1992. 
Swietlicki, E., Zhou, J., Berg, O.H., Martinsson, B.G., Frank, G., Cederfelt, S-I, Dusek, U., Berner, A., Birmili, W, Wiedensohler, A., Yuskiewicz, B. and Bower, K.N. ; A Closure Study of Sub-micrometer Aerosol Particle Hygroscopic Behaviour, Atmospheric Research, 50, 205-240, 1999

Swietlicki, E., Zhou, J., Covert, D. S., Hameri, K., Busch, B., Vakeva, M., Dusek, U., Berg, O. H., Wiedensohler, A., Aalto, P., Makela, J., Martinsson, B. G., Papaspiropoulos, G., Mentes, B., Frank, G., and Stratmann, F.: Hygroscopic properties of aerosol particles in the north-eastern Atlantic during ACE-2, Tellus, 52B, 201-227, 2000.

Tang, I. N.and Munkelwitz, H. R.: Water activities, densities, and refractive indices of aqueous sulfates and sodium nitrate droplets of atmospheric importance, J. Geophys. Res., 99, 18 801-18 808, 1994.
Van Dingenen, R., Raes, F., Putaud, J.-P., et al.: A European aerosol phenomenology-1: physical characteristics of particulate matter at kerbside, urban, rural and background sites in Europe, Atmos. Environ., 38, 2561-2577, 2004.

Virkkula, A., Van Dingenen, R., Raes, F., and Hjorth, J.: Hygroscopic properties of aserosol formed by oxidation of limonene, $\alpha$-pinene, and $\beta$-pinene, J. Geophys. Res., 104, 3569-3579, 1999.

Weingartner, E., Saathoff, H., Schnaiter, M., Streit, N., Bitnar, B., and Baltensperger, U.: Absorption of light by soot particles: determination of the absorption coefficient by means of aethalometers, J. Aerosol Sci., 34, 1445-1463, 2003.

Zhang, X. Q., McMurry, P. H., Hering, S. V., and Casuccio, G. S.: Mixing characteristics and water content of submicron aerosols measured in Los Angeles and at the Grand Canyon, Atmos. Environ., 27A (10), 1593-1607, 1993. 